\title{
DNA metabarcoding of zooplankton communities: species diversity and seasonal variation revealed by 185 rRNA and COI
}

\author{
Lina Zhao ${ }^{1}$, Xue Zhang ${ }^{1}$, Mengyue Xu ${ }^{1}$, Ying Mao ${ }^{1}$, Yuan Huang ${ }^{\text {Corresp. } 1}$ \\ ${ }^{1}$ College of Life Sciences, Shaanxi Normal University, Xian, Shaanxi, China \\ Corresponding Author: Yuan Huang \\ Email address: yuanh@snnu.edu.cn
}

Background. Zooplankton is an important component of aquatic organisms and has important biological and economical significance in freshwater ecosystems. However, traditional methods that rely on morphology to classify zooplankton require expert taxonomic skills. Moreover, traditional classification methods are time-consuming and labor-intensive, which is not practical for the design of conservation measures and ecological management tools based on zooplankton diversity assessment.

Methods. We used DNA metabarcoding technology with two different markers: the nuclear small subunit ribosomal RNA (18S rRNA) and mitochondrial cytochrome c oxidase (COI), to analyze 72 zooplankton samples collected in 4 seasons and 9 locations from the Sanmenxia Reservoir. We investigated seasonal changes in the zooplankton community and their relationship with water environmental factors.

Results. A total of 190 species of zooplankton were found, belonging to 12 phyla, 24 classes, 61 orders, 111 families, and 174 genera. Protozoa, especially ciliates, were the most diverse taxa. Richness and relative abundance of zooplankton showed significant seasonal changes. Both alpha and beta diversity showed seasonal trends: the diversity in summer and autumn was higher than that in winter and spring. The zooplankton diversity was most similar in winter and spring. By correlating metabarcoding data and water environmental factors, we proved that water temperature, chemical oxygen demand, total nitrogen and ammoniacal nitrogen were the main environmental factors driving the seasonal changes in zooplankton in the Sanmenxia Reservoir. Water temperature, followed by total nitrogen, were the most influential factors. This study highlights the advantages and some limitations of zooplankton molecular biodiversity assessment using two molecular markers.

Subjects: Ecology, Biodiversity, Freshwater Biology, Molecular Biology

Keywords: zooplankton diversity, metabarcoding, seasonal variation, water environmental factor, Sanmenxia Reservoir 
5 Lina Zhao ${ }^{1}$, Xue Zhang ${ }^{1}$, Mengyue $\mathrm{Xu}^{1}$, Ying Mao ${ }^{1}$, Yuan Huang ${ }^{1 *}$

$7 \quad{ }^{1}$ College of Life Sciences, Shaanxi Normal University, Xi’an 710062, China;

8 Linazhao@snnu.edu.cn (L.Z.); zxsnowwww@gmail.com (X.Z.); xumengyue709@163.com;

9 maoying0423@163.com (Y.M.)

$11 *$ Corresponding author

12 E-mail: yuanh@snnu.edu.cn (YH)

\section{Abstract}

15 Background. Zooplankton is an important component of aquatic organisms and has important

16 biological and economical significance in freshwater ecosystems. However, traditional methods 
17 that rely on morphology to classify zooplankton require expert taxonomic skills. Moreover,

18 traditional classification methods are time-consuming and labor-intensive, which is not practical

19 for the design of conservation measures and ecological management tools based on zooplankton

20 diversity assessment.

21 Methods. We used DNA metabarcoding technology with two different markers: the nuclear small

22 subunit ribosomal RNA (18S rRNA) and mitochondrial cytochrome c oxidase (COI), to analyze

2372 zooplankton samples collected in 4 seasons and 9 locations from the Sanmenxia Reservoir. We

24 investigated seasonal changes in the zooplankton community and their relationship with water

25 environmental factors.

26 Results. A total of 190 species of zooplankton were found, belonging to 12 phyla, 24 classes, 61

27 orders, 111 families, and 174 genera. Protozoa, especially ciliates, were the most diverse taxa.

28 Richness and relative abundance of zooplankton showed significant seasonal changes. Both alpha

29 and beta diversity showed seasonal trends: the diversity in summer and autumn was higher than

30 that in winter and spring. The zooplankton diversity was most similar in winter and spring. By

31 correlating metabarcoding data and water environmental factors, we proved that water

32 temperature, chemical oxygen demand, total nitrogen and ammoniacal nitrogen were the main

33 environmental factors driving the seasonal changes in zooplankton in the Sanmenxia Reservoir.

34 Water temperature, followed by total nitrogen, were the most influential factors. This study

35 highlights the advantages and some limitations of zooplankton molecular biodiversity assessment

36 using two molecular markers. 


\section{INTRODUCTION}

38 Protecting the biodiversity of freshwater ecosystems is particularly important in the 21 st century.

39 Freshwater ecosystems not only contain the most concentrated biodiversity of all ecosystems on

40 the planet but are also the most endangered ecosystems worldwide (Dudgeon et al. 2006). These

41 ecosystems are susceptible to anthropogenic factors, such as climate change, eutrophication, and

42 the introduction of nonnative species, all of which will lead to a reduction in biodiversity (Dudgeon

43 et al. 2006; Revenga et al. 2005; Vörösmarty et al. 2010). Over the past few decades, the

44 biodiversity of freshwater ecosystems has decreased significantly more than that of terrestrial or

45 marine ecosystems (Sala et al. 2000). Although data on the extinction rate of freshwater

46 ecosystems are limited to North America (Ricciardi \& Rasmussen 1999), these data hint at a global

47 crisis of freshwater biodiversity (Abell et al. 2008). Therefore, protecting the biodiversity of

48 freshwater ecosystems is a key priority. However, protection requires a detailed understanding of

49 this biodiversity.

50 Zooplankton, including protozoans, rotifers and microcrustaceans (cladocerans and

51 copepods) (Allan 1976; Pace \& Orcutt Jr 1981), have important biological and economic value in

52 freshwater ecosystems. Not only are zooplankton the major consumers in aquatic ecosystems, they

53 are also an important food source for fish larvae and, thus, have an important role in connecting

54 primary producers with higher nutritional consumers (Allan 1976; Banse 1995; Lubzens 1987).

55 Moreover, due to the influence of abiotic factors (such as water temperature) and seasonal changes

56 in biological factors, zooplankton communities also exhibit seasonal change patterns. In addition, 
57 zooplankton are very sensitive to external disturbances, and they are commonly used

58 as indicators of water quality (Branco et al. 2002; Gannon \& Stemberger 1978; Oh et

59 al. 2017; Sládeček 1983). For example, Brachionus calyciflorus can be used as an indicator of

60 eutrophic water bodies (Gannon \& Stemberger 1978), which has far-reaching importance in water

61 environment monitoring. However, the fragility of the zooplankton itself, the small size, the

62 difficulty of obtaining observations, and the species variety of zooplankton have limited the

63 understanding of zooplankton diversity (Machida et al. 2009), which is not conducive to the

64 protection of aquatic biodiversity. Among freshwater ecosystems, reservoirs have always been a

65 subject of interest. Reservoirs enable river systems to be strongly regulated while providing the

66 convenience of hydropower for human production activities (Yang \& Lu 2014). However,

67 damming considerably perturbs the river's export of organic carbon to the ocean (Gao et al. 2019;

68 Maavara et al. 2017). In addition, the water residence time of the storage reservoir is

69 significantly increased and the flow velocity is obviously decreased after dam closure

70 (Friedl \& Wüest 2002), which hinders the movement of aquatic organisms, and alters their

71 habitats thus has a significant effect on aquatic biodiversity (Vörösmarty et al. 2010). Direct and

72 indirect habitat changes are a major factor driving the decline or extinction of freshwater biological

73 species, especially for species with limited diffusion capacity (Pimm et al. 2014; Revenga et al.

74 2005), such as zooplankton.

75 Although zooplankton have important biological and economic value in

76 freshwater ecosystems, traditional taxonomic methods used to characterize 
77 zooplankton communities are not sufficient for large-scale biodiversity research. The

78 limitations of traditional morphological identification methods cannot be completely

79 overcome in the short term (Trebitz et al. 2017). On the one hand, traditional

80 morphological classification methods are not only time consuming and labor

81 intensive but also lack resources for species identification (such as increasingly

82 limited funding to support taxonomic scientists for scientific research) (Creer et al.

83 2016; Pawlowski et al. 2016). On the other hand, traditional morphological

84 identification methods require scientific researchers to be proficient in taxonomy, but

85 academia currently lacks experienced taxonomists (Pawlowski et al. 2016). In

86 addition, a large amount of classification research work may also contain

87 classification errors (Sundermann et al. 2005). To overcome the limitations of

88 conventional morphology-based methods, improved methods are urgently needed to

89 detect zooplankton species in freshwater ecosystems more quickly, sensitively, and

90 effectively (Xiong et al. 2020). DNA metabarcoding technology can quickly alleviate

91 this situation and has proven to be a powerful tool for large-scale biodiversity

92 research (Beng et al. 2016; Ji et al. 2013; Shokralla et al. 2012). This technology

93 assigns ecological value to the taxonomic operational units (OTUs) generated by

94 high-throughput sequencing data and quickly, economically and efficiently realizes

95 the classification and identification of environmental DNA (Fernando 2002;

96 Pawlowski et al. 2016), making an important and unique contribution in the field of 
97 ecology (Xie et al. 2017; Zhang et al. 2018). DNA metabarcoding technology provides

98 detailed information about zooplankton biodiversity and can support biodiversity conservation

99 (Xiong et al. 2020). In addition, it has been successfully used to track seasonal changes

100 in the zooplankton community (Berry et al. 2019; Mwagona et al. 2018; Nandini et

101 al. 2008; Tan et al. 2004; Vanderploeg et al. 2012). Metabarcoding technology sensitively

102 reflects the relationship between the abundance of the zooplankton community and environmental

103 factors and provides methodological support for exploring the water environmental factors that

104 drive seasonal changes in zooplankton (Yang et al. 2017a). Most biodiversity studies based on

105 DNA metabarcoding technology use a single molecular marker method (Amaral-Zettler et al.

106 2009; Bucklin et al. 2019; Chain et al. 2016), but the taxon scope of the study of single molecular

107 markers is limited (Drummond et al. 2015; Giebner et al. 2020). However, the multigene-based

108 metabarcoding method can increase the taxonomic breadth, which is especially important for

109 assessing the biodiversity of highly diverse groups such as zooplankton.

110 Considering the dramatic changes in ecology, water transparency, nutritional status, the

111 densities in the downstream Sanmenxia Reservoir and the strong dependence of zooplankton

112 richness on the lake conditions of the dam (creating a stable environment for the survival and

113 reproduction of different zooplankton populations), we hypothesize that the Sanmenxia Reservoir

114 has a particularly rich zooplankton community. Moreover, due to seasonal changes in the water

115 environment, the zooplankton community is likely to exhibit a seasonal change pattern in the

116 reservoir, and this seasonality is closely related to water environmental factors. However, it is not 
117 clear which water environmental factors have an impact on the richness and relative abundance of

118 the zooplankton community in the Sanmenxia Reservoir or which factors have the strongest

119 influence. To verify the above hypothesis, we attempt to characterize the zooplankton diversity

120 and water environmental factors in the Sanmenxia Reservoir by obtaining seasonal (summer,

121 autumn, winter and spring in July 2017, October 2017, January 2018 and March 2018,

122 respectively) zooplankton samples and water samples. We used a multigene approach with two

123 independently evolved markers, the nuclear small subunit ribosomal RNA (18S rRNA v4 region;

124 Hadziavdic et al. 2014) and and the mitochondrial cytochrome c oxidase (COI; Leray \& Knowlton

125 2015). The main purposes of our study are (1) to explore the composition of the zooplankton

126 community in the Sanmenxia Reservoir, (2) to reveal the dynamics of seasonal changes in the

127 zooplankton community, and (3) to determine the main water environmental factors that drive the

128 seasonal changes in zooplankton diversity in the reservoir area.

MATERIALS AND METHODS

Study area, zooplankton sample collection and measurement of water environmental factors

132 The Sanmenxia Reservoir, which is located in the lower reaches of the Middle Yellow River basin

133 in China, was effectively completed in 1960. The reservoir is the first large-scale water

134 conservancy project built on the Yellow River and controls $89 \%$ of the water in the Yellow River

135 basin (Chen et al. 2017; Wang et al. 2005). The reservoir area is in a warm temperate continental 
136 monsoon climate. The interannual temperature fluctuates within the range of $-18.3^{\circ} \mathrm{C} \sim 42.3^{\circ} \mathrm{C}$, and

137 the average annual temperature is $14.1^{\circ} \mathrm{C}$ (Zhang et al. 2012). According to the geographical

138 features of the Sanmenxia Reservoir and the field investigation, nine sampling points (as 9

139 biological replicates in this study) with representative habitats (the front and rear of the dam of

140 Sanmenxia Reservoir) were set up in the reservoir area to collect samples (three replicates each

141 site) in summer, autumn, winter and spring in July 2017, October, 2017, January 2018 and April

142 2018, respectively (Fig. S1). Geographical coordinates of the sampling site were collected with a

143 global positioning system (GPS) (Garmin Legend, Garmin USA). Zooplankton samples were

144 collected by filtering $20 \mathrm{~L}$ of water using plankton nets (46- $\mu \mathrm{m}$ mesh). The plankton net was

145 dragged along the water surface repeatedly in a " $\infty$ " shape at a depth of $0.3 \mathrm{~m}$ for 5 minutes to

146 collect and concentrate samples. Then, the samples were transferred into a $50 \mathrm{~mL}$ centrifuge tube

147 and immediately preserved in $95 \%$ ethanol. In the laboratory, the zooplankton samples were

148 further filtered through $0.22 \mu \mathrm{m}$ microporous filter paper (Whatman, UK) to remove excess water,

149 placed in a $5 \mathrm{~mL}$ centrifuge tube, and then stored at $-80^{\circ} \mathrm{C}$ until DNA extraction could be 150 completed.

151 During the zooplankton sampling period, additional $500 \mathrm{~mL}$ water samples were collected at

152 each sampling site to measure chemical oxygen demand (COD), total nitrogen (TN), total 153 phosphorus (TP), ammonia nitrogen $\left(\mathrm{NH}_{4}-\mathrm{N}\right)$ and $\mathrm{pH}$. These measurements were taken in the laboratory of Shaanxi Normal University. Water temperature (WT) and dissolved oxygen (DO) 
156

157

158

159

160

161

162

163

164

165

166

167

168

169

170

171

172

173

174

China).

\section{DNA extraction, PCR amplification, library construction and high-throughput sequencing} (HTS)

The total DNA of the zooplankton community was purified by mixing DNA isolated from three samples from each sampling site using the DNeasy Blood and Tissue Kit (Qiagen, Germany). The three biological replicates of each sampling site were pooled to yield more DNA. DNA quality was monitored using a NanoDrop 2000 (Thermo Scientific, USA) and 1\% agarose gel electrophoresis. Mitochondrial cytochrome c oxidase I (COI) was amplified by using the universal COI primers mlCOIintF and jgHCO2198 (Geller et al. 2013; Leray \& Knowlton 2015), and the V4 region of the nuclear small subunit ribosomal RNA (18S rRNA) was amplified by using HPLC-purified PCR primers (Nolte et al. 2010) (Table S1). PCR was performed with $25 \mu \mathrm{L}$ reactions for each sample, including $1 \mu \mathrm{L}$ of DNA template $(30 \mathrm{ng} / \mu \mathrm{L}), 1 \mu \mathrm{L}$ of primers $(10 \mu \mathrm{M})$, $19.9 \mu \mathrm{L}$ of ultrapure water, $2.5 \mu \mathrm{L}$ of High-Fidelity PCR buffer $(10 \times), 0.5 \mu \mathrm{L}$ of $\mathrm{dNTP}$ mix $(10 \mathrm{mM})$ and $0.1 \mu \mathrm{L}$ of Platinum Taq DNA polymerase (Invitrogen, USA). The PCR reaction procedure was as follows. $18 \mathrm{~S}: 95^{\circ} \mathrm{C}$ for $3 \mathrm{~min} ; 35$ cycles at $95^{\circ} \mathrm{C}$ for $45 \mathrm{~s} ; 50^{\circ} \mathrm{C}$ for $50 \mathrm{~s} ; 72^{\circ} \mathrm{C}$ for $45 \mathrm{~s}$; and $72^{\circ} \mathrm{C}$ for $10 \mathrm{~min}$; COI: $95^{\circ} \mathrm{C}$ for $10 \mathrm{~min} ; 16$ cycles at $94^{\circ} \mathrm{C}$ for $10 \mathrm{~s} ; 62^{\circ} \mathrm{C}$ for $30 \mathrm{~s}$ (decreasing by $1^{\circ} \mathrm{C}$ per cycle); $68^{\circ} \mathrm{C}$ for $60 \mathrm{~s} ; 25$ cycles at $94^{\circ} \mathrm{C}$ for $10 \mathrm{~s} ; 46^{\circ} \mathrm{C}$ for $30 \mathrm{~s} ; 68^{\circ} \mathrm{C}$ for $60 \mathrm{~s} ; 72^{\circ} \mathrm{C}$ for $10 \mathrm{~min}$ extension; and $4^{\circ} \mathrm{C}$ insulation. Then, the PCR products of the same sample 
175 (three PCR replicates per sample) were mixed and subjected to 2\% agarose gel electrophoresis.

176 PCR product was recycled by cutting the gel using an AxyPrepDNA gel extraction kit (Axygen

177 Biosciences, USA), and subjected to Tris_HCl elution and 2\% agarose electrophoresis. After

178 purification, a standardized procedure for qualified PCR products was followed to form an

179 amplicon library, and a MiSeq Reagent Kit v2 (500 cycle) was used to perform high-throughput

180 sequencing of $2 \times 250 \mathrm{bp}$ reads on the Illumina MiSeq platform (Allwegene, China).

181 Data processing

182 Initial quality control was completed using Trimmomatic (Bolger et al. 2014), a 50 bp window

183 size was set, and bases with average Phred quality score less than 20 were trimmed. The primer

184 sequence was removed using Cutadapt (Martin 2011). Merging of raw paired-end reads was

185 conducted using FLASH (Magoč \& Salzberg 2011) with more than $10 \mathrm{bp}$ in the minimum overlap

186 sequences, and the maximum allowable mismatch ratio not exceeding 0.1 . Recognition and

187 removal of chimeric sequences were conducted using UCHIME (Edgar et al. 2011). OTU

188 clustering was performed using UPARSE (namely, USEARCH was used to cluster OTUs

189 according to $97 \%$ similarity sequences, excluding single sequences, obtain representative

190 sequences and then map all their sequences according to 97\% similarity to OTUs to form an OTU

191 list) pipeline (Edgar 2013). OTU annotation was conducted on the representative sequences of

192 each OTU against Silva (18S rRNA) and the BOLD reference database (COI) (Altschul et al. 1990;

193 Pruesse et al. 2007; Ratnasingham \& Hebert 2007). The species names of OTUs were designated

194 as sequence identity exceeding 97\%, and the genus names of OTUs were designated as sequence 
195

196

197 198

identity between $90 \%$ and $97 \%$. If an OTU could not be assigned to a species, it was assigned to a higher taxonomic level. We also removed all bacteria, fungi, and Viridiplantae from the OTU annotation tables to focus exclusively on zooplankton for the purpose of this study.

\section{Zooplankton diversity analysis}

Statistical analyses were performed by using the "vegan" package in R v.3.6.3 (Oksanen et al. 2010; Team 2013). Rarefaction curves were used to measure the saturation of zooplankton samples. Venn diagrams were used to show the number of different taxa recovered by using $18 \mathrm{~S}$ (blue) or COI (yellow) at different taxonomic levels. Bar charts were used to reflect the difference in OTU richness and relative abundance produced by DNA metabarcoding technology in $18 \mathrm{~S}$ (blue) or COI (yellow). Bubble plots were used to reflect the composition and seasonal variation in the zooplankton community. Alpha diversity was characterized by the Shannon and ACE indices, which were drawn by box plotting. In this process, since the data did not obey a normal distribution, the Kruskal-Wallis nonparametric test was used to determine whether seasonal changes in zooplankton diversity were significantly different. Subsequently, since the OTU richness data obeyed a normal distribution and homogeneity of variance, analyses of variance (ANOVA) were selected and performed using Tukey's honest significant difference (Tukey HSD) tests to analyze whether the richness of each zooplankton group differed significantly among seasons. Bar charts were also used to characterize the seasonal changes in the relative abundance of each zooplankton group, and the Welch $t$ test was used to determine whether their seasonal changes were significant in adjacent sampling seasons. To evaluate the seasonal variation in the 
215 zooplankton community between samples, a principal coordinate analysis (PCoA) was used to

216 cluster the samples by sampling season based on the Jaccard dissimilarity index and Bray-Curtis

217 dissimilarity index, and pairwise comparisons of all sampling seasons were performed using

218 PERMANOVA (Anderson 2001). An analysis of similarity (ANOSIM) was also used for further

219 evaluation. According to the characteristics of the measured water environmental factor data, the

220 relationship between the variables was analyzed using Spearman's correlation analysis with

221 Bonferroni correction to account for multiple testing. To investigate the water environmental

222 factors that drive seasonal changes in the zooplankton community, the OTU data matrix was

223 related to the water environmental factor matrix by using the partial Mantel test, and relative

224 abundance data were combined with water environmental factors for canonical correspondence

225 analysis (CCA). An Adonis analysis (permutations: 999) was used to test the contribution

226 (variation, R2) and significance of each water environmental factor.

\section{Results}

\section{Results of amplicon sequencing}

230 We metabarcoded a total of 36 samples for each marker (9 locations per season, for a total of four

231 seasons). After the Illumina sequence passed all filtering procedures, 2,185,317 and 910,137 high-

232 quality reads (including non-plankton metazoans) were obtained from the 18S rRNA and COI

233 metabarcoding, respectively. In the $18 \mathrm{~S}$ rRNA dataset, the sequencing depth per sample ranged 
234 from 5510 to 116,411 , with an average of 60,703 . In the COI dataset, the sequencing depth per 235 sample ranged from 7057 to 68,313 , with an average of 25,282 (Table S2). The OTUs of single 236 reads were excluded from further analysis to reduce the possible effects of spurious signals. This 237 exclusion could conservatively remove potential misamplified fragments, although they may 238 represent very low-abundance zooplankton groups. The rarefaction curves of 72 zooplankton 239 samples stabilized with increasing sequencing depth, which indicated that most of the sampling 240 points were properly sampled and that the data tended to be saturated (Fig. S2). DNA 241 metabarcoding of zooplankton samples resulted in the identification of 495 OTUs from the 18S 242 rRNA gene, and 1099 OTUs from the COI gene. Approximately 5.25\% (26 of 495 OTUs) observed 243 in the $18 \mathrm{~S}$ rRNA datasets could only be identified to kingdom and were labeled "Eukaryota" or 244 "Metazoa". Approximately 3.46\% and 0.54\% (38 and 6 of 1099 OTUs, respectively) were labeled

245 "Invertebrate environmental sample" and "Arthropoda environmental sample" in the COI datasets, 246 respectively. Approximately 64.44\% (319 of 495 OTUs, 18S rRNA) and 35.94\% (395 of 1099

247 OTUs, COI) of the OTUs were classified as zooplankton, and the remaining OTUs were annotated 248 as Insecta, Gastropoda, etc. (Table.S3). The number of zooplankton OTUs ranged from 26 to 148 249 (18S rRNA) and 49 to 146 (COI) in each sample (Table 1).

\section{Zooplankton community composition}

251 There were differences in the number of zooplankton taxa identified by the two markers at different 252 taxonomic levels (Table 2, Fig. 1). A total of 12 phyla were identified in this study, including 24 253 classes, 61 orders, 111 families, 174 genera and 190 species. Of the 319 nonsingleton zooplankton 
254 OTUs in the 18S rRNA gene, 12 phyla were represented across 23 classes, 54 orders, 83 families

255

256

257

258

259

260

261

262

263

264

265

266

267

268

269

270

271

272

273

and 110 genera (Table 2). Of the 395 nonsingleton zooplankton OTUs in the COI gene, 4 phyla

were represented across 7 classes, 19 orders, 42 families and 80 genera (Table 2). At the phylum

level, the four phyla detected by the COI were also be recovered with $18 \mathrm{~S}$. The corresponding percentages were $85.71 \%$ for class, $63.16 \%$ for order, $33.33 \%$ for family, $20.00 \%$ for genus, and 9.4\% for species-level taxa (Fig. 1).

The richness (Fig. 2A) and species diversity (Fig. 1GHI) of the same zooplankton groups showed differences in the results identified by the two markers, with Copepoda richness the only exception (Fig. 2A). Protozoa was the most abundant group in the 18S rRNA, accounting for $68.03 \%$ (217 OTUs) and 76.19\% (64 species) of zooplankton richness and species diversity, respectively, and only $14.18 \%$ (56 OTUs) and 18.80\% (22 species), respectively,in COI. Rotifera was the most abundant group (57.47\%, 227 OTUs; 51 species, $43.59 \%)$ in COI but only accounted for $8.46 \%$ (27 OTUs) and $11.90 \%$ (10 species) of richness and diversity, respectively, in $18 \mathrm{~S}$ rRNA. Copepoda was the second most abundant taxon between the two markers; its OTUs richness was similar (73, 71OTUs), and 11 and 30 species were identified in the COI and 18S rRNA samples, respectively. The least diverse taxonomic groups was Cladocera (2 OTUs, 18S rRNA; 41 OTUs, COI) using both markers, and 0 and 14 species were identified respectively. In addition, 11 species were identified by both markers (Fig. 1GHI): 2 species of Protozoa, namely, Vermamoeba vermiformis and Reclinomonas americana, 4 species of rotifers, namely, Adineta vaga, Asplanchna sieboldi, Brachionus calyciflorus and Testudinella clypeata, and 5 species of 
274 copepods, namely, Megacyclops viridis, Mesocyclops dissimilis, Mesocyclops pehpeiensis,

275 Microcyclops varicans and Pseudodiaptomus inopinus. Brachionus calyciflorus was detected in

276 all (72) zooplankton samples (Fig. S3). Eucyclops macruroides, Sinocalanus sinensis and

277 Brachionidae sp. SHDT150710, and Keratella cochlearis were also present in each zooplankton

278 sample of $18 \mathrm{~S}$ rRNA or COI genes (Fig. S3).

279 The relative abundance of the same zooplankton group differed between the two

280 markers.(Fig.2B). 18S Copepoda had significantly higher relative abundance than other

281 zooplankton taxa, but 18S Cladocera had the lowest relative abundance. In COI, Rotifera had the

282 highest relative abundance, which was similar to that of Copepoda. However, the relative

283 abundance of Protozoa was low according to both markers.

284 Seasonal dynamics of zooplankton diversity

285 The Shannon diversity and ACE index observed in the metabarcoding datasets of each molecular

286 marker were similar, and all showed a maximum in summer or autumn and a minimum in spring

287 or winter (Table 1). Moreover, the entire zooplankton community assemblages showed significant

288 seasonal changes, including the richness estimators ACE, and the diversity estimator Shannon

289 (Fig. 3). The overall trend showed high diversity in summer and autumn and low diversity in winter

290 and spring.

291 To explore seasonal changes in each zooplankton group, we performed ANOVA on the

292 richness datasets of zooplankton at OTU levels (Fig. 4). The results showed that the richness of 
293

294

295

296

297

298

299

300

301

302

303

304

305

306

307

308

309

310

311

312

zooplankton groups, except for the 18S Cladocera, had significant seasonal changes (Tukey HSD,

$p<0.01$, Fig. 4), and the species diversity of most zooplankton groups was significantly higher in

summer and autumn than in winter and spring. In addition, the trend in seasonal changes in the

relative abundance of Rotifera was consistent in the two molecular markers, and Copepoda was

no exception. From summer to autumn in 2017 , the relative abundance of Rotifera decreased from

$21.57 \%(18 \mathrm{~S})$ and $32.78 \%(\mathrm{COI})$ to $3.36 \%$ and $11.49 \%$, respectively (Fig. 5AD), and then increased to $42.22 \%$ and $67.20 \%$ in winter 2018 (Fig. 5BE) and finally decreased to $35.20 \%$ and $59.92 \%$ in spring 2018 (Fig. 5CF). The change tendency of the relative abundance of 18S Protozoa was consistent with that of Rotifera, and the trend was only consistent with that of the COI

Protozoa from winter to spring (Fig. 5F). The relative abundance of Cladocera was consistent with the change trend in $18 \mathrm{~S}$ Copepoda. However, for COI, the relative abundance increased from summer $(8.37 \%)$ to winter $(15.41 \%)$ and then decreased in spring, when it reached a minimum (6.31\%) (Fig. 5DEF). In fact, the relative abundance of most zooplankton groups, except for the richness, also showed significant seasonal variation between adjacent sampling seasons (Welch $t$ test, $\mathrm{p}<0.05)$. However, the relative abundance of Cladocera showed no significant seasonal changes between adjacent sampling seasons (Welch $t$ test, $\mathrm{p}>0.05$ ), although its relative abundance based on COI was obviously higher than that of the 18S rRNA gene. with a $75 \%$ confidence interval, the samples for most sampling seasons were divided into three 
313 distinct clusters. Two distinct clusters were formed separately in summer and autumn, and another

314 large cluster was formed in winter and spring, and there was no overlap between seasons other

315 than between winter and spring (Fig. 6). Thus, the zooplankton communities in winter and spring

316 were more similar to each than were those in the summer and autumn.

317 In terms of relative abundance, the zooplankton communities during winter and spring were

318 dominated by Rotifera and Copepoda in the $18 \mathrm{~S}$ metabarcoding datasets, and their relative

319 abundances were $42.22 \%$ and $35.20 \%$ (Rotifera) and 54.15\% and 63.39\% (Copepoda) (Fig. 5C),

320 respectively, within which Eucyclops and Brachionus were predominant (Fig. 7A), contributing

$32136.57 \%$ and $33.59 \%$ to the similarity of the zooplankton community in winter and spring,

322 respectively. Conversely, the autumn zooplankton samples were nearly all annotated as Copepoda

323 (95.81\%) (Fig. 5A), including Eucyclops and Mesocyclops (Fig. 7A). The summer zooplankton

324 samples also had a small number of Rotifera (21.57\%), but the abundance was far lower than the

325 relative abundance of Rotifera in winter and spring, except for a large number of Copepoda

326 (Mesocyclops and Undinula) (77.16\%). Although the dominant group changed slightly with

327 different markers, it did not affect the trend. In the COI metabarcoding datasets, the zooplankton

328 communities in winter and spring were dominated by Rotifera $(67.20 \%, 59.92 \%)$ (Fig. 5F), mainly

329 Brachionus, which contributed $27.92 \%$ to the community similarity between the two seasons. In

330 autumn, 78.59\% of the sequences were annotated as Copepoda (Fig. 5D), mainly including

331 Eucyclops (contribution rate of 20.44\%) (Fig. 7B), but the relative abundances of Rotifera and

332 Cladocera were similar, accounting for $11.49 \%$ and $8.95 \%$, respectively. The relative abundance 
333 of dominant groups in summer COI showed similar trends to those of 18S rRNA.

334

335

336

337

338

339

340

341

342

343

344

345

346

In general, the entire zooplankton community assemblages showed significant seasonal changes (Fig. 6, PERMANOVA, $p<0.001$ ). In addition, the ANOSIM results further indicated that the zooplankton community had significant seasonal variations (Table S4).

\section{Seasonal changes in zooplankton diversity driven by water environmental factors}

The measured values (mean values) of water environmental factors in the Sanmenxia Reservoir during all four seasons (time) in the study period are shown in Table 3. Each water environmental factor showed statistically significant differences between seasons (Kruskal-Wallis, $p<0.01$ ). With the change in sampling season, the WT fluctuated, ranging from 2.0 (winter) to $33.2^{\circ} \mathrm{C}$ (summer); the recorded $\mathrm{TN}$ concentration showed an increase and reached the highest concentration in spring $(5.3 \pm 0.16 \mathrm{mg} / \mathrm{L})$; the DO increased from summer and reached the highest concentration in winter $(8.31 \pm 0.49 \mathrm{mg} / \mathrm{L})$ and then decreased to the lowest concentration in spring $(6.16 \pm 0.16 \mathrm{mg} / \mathrm{L})$. The $\mathrm{pH}, \mathrm{COD}, \mathrm{TP}$, and $\mathrm{NH}_{4}-\mathrm{N}$ showed synchronous changes that fell from summer to autumn, rose again from autumn to winter, and eventually fell from winter to spring. we performed partial (geographic distance-corrected) Mantel tests to correlate the DNA metabarcoding datasets and the distance matrix of water environmental factors based on Euclidian distances. The results showed that $\mathrm{WT}, \mathrm{COD}, \mathrm{TN}$ and $\mathrm{NH}_{4}-\mathrm{N}$ were the main water environmental factors that drive seasonal changes in zooplankton richness (Fig. 8). WT had a significant positive 
352

353

354

355

356

357

358

359

360

361

362

363

364

365

366

367

368

369

370

correlation (Spearman's, $p<0.05$ ) with the richness of most zooplankton groups. Moreover, the water environmental factors that drive seasonal changes in zooplankton groups changed slightly with different groups in the same molecular marker, such as Rotifera and Copepoda. Due to the different taxa and richness identified by different molecular markers, the environmental factors that drive the seasonal changes in these four zooplankton groups were not completely consistent between the two molecular markers.

The CCA results showed that six water environmental factors explained $59.67 \%$ and $50.29 \%$ of the zooplankton community variance based on the relative abundance in CCA axis 1 and $32.22 \%$ and $29.39 \%$ in axis 2 , respectively (Fig. 9). Among all the factors, WT was the most powerful driving factor, followed by TN (Table S5). However, DO was not found to directly affect the seasonal variation in zooplankton diversity in the current analysis (partial Mantel test, $p>0.05$; Adonis, $p>0.05)$.

\section{Discussion}

\section{Zooplankton diversity}

DNA metabarcoding technology is a powerful tool for large-scale biodiversity research. Multigene metabarcoding is a particularly promising approach. A total of 111 families, 174 genera and 190 species were identified in the four sampling seasons by using $18 \mathrm{~S}$ and COI as markers. Compared with the 48 species (29 species of Protozoa, 16 species of Rotifera, 2 species of 
371 Copepoda, 1 species of Cladocera) surveyed in the reservoir area in 1985 (Qiaoyu \& Zhifeng

372 2005), the number of zooplankton species identified by the metabarcoding method was

373 significantly higher. Based on this significant increase in zooplankton species, we believe that a

374 significant change has occurred in the species composition of zooplankton in the Sanmenxia

375 Reservoir. However, we realize that the previous research used a classification method based on

376 traditional morphology, which was different from the metabarcoding method we used, and the data

377 analysis methods and sampling locations were also inconsistent. Therefore, studies on zooplankton

378 diversity should be conducted by using the same method and sampling location to obtain more

379 comprehensive and reliable results ( $\mathrm{Li}$ et al. 2019b)

We found that the number of zooplankton species identified by the two molecular markers is

381

382

383

384

385

386

387

388

389

390

larger than that of any single molecular marker in this study. The simultaneous use of two molecular markers can improve the detection of species (Zhang et al. 2018), and make the results of zooplankton diversity research more comprehensive. Different markers not only have different taxonomic resolution but also complement one another (Bucklin et al. 2016; Giebner et al. 2020). The taxa identified by the two markers were different, and we suspect two principal reasons for this difference. Firstly, it could be caused by the different amplification ability of PCR primers for different organisms. Each molecular marker gene has different amplification efficiency for each taxonomic group under the amplification of different universal primers, resulting in different amplified taxa. In this process, PCR amplification bias may be introduced due to universality of the primers, annealing temperature, and the number of replication cycles, etc. (Engelbrektson et 
391 al. 2010). Secondly, the use of different reference databases can also lead to differences

392 in taxonomic identification. To more comprehensively identify zooplankton taxa, we need to

393 use both a reference database with taxonomic integrity and that is geographically comprehensive

394 (Bucklin et al. 2016), but we did not choose the NCBI nt database. Instead, we selected the

395 SILVA, and BOLD databases as references for $18 \mathrm{~S}$ rRNA and COI sequences,

396 respectively. The SILVA database is suitable for annotating $18 \mathrm{~S}$ rRNA sequences to

397 a more refined taxonomic level compared to the NCBI nt database(Lindeque et al.

398 2013); the BOLD database is mainly based on COI barcodes and currently contains

399 over 4 million sequences of more than 5 million different species (Wangensteen et

400 al. 2018) Moreover, the purpose of our research was to more comprehensively identify and

401 classify zooplankton diversity rather than compare the diversity and taxonomy of different

402 molecular markers, although the NCBI nt database can facilitate the comparison of multiple

403 molecular markers in the same database (Djurhuus et al. 2018). Therefore, we chose two different

404 reference databases. Interestingly, all 18 classes found only in the 18S rRNA identification results

405 were protozoans, such as Dinophyceae, Phyllopharyngea, and Litostomatea so and on. We think

406 that this sensitivity to protozoans may arise from their closely connection with the PCR primers

407 and reference database we selected. 18S rRNA datasets were mainly used to identify Protozoa in

408 this study, and the PCR primers and reference database of the 18S rRNA datasets we selected were

409 also biased to detect Protozoa, which further indicates that the choice of reference database and

410 primer has a great impact on the detection results. Moreover, it should be pointed out that no matter 
411 which database is used, the annotation of the OTU may be biased or blocked due to the absence of

412 the reference sequence(Djurhuus et al. 2018). The $18 \mathrm{~S}$ marker has a low taxonomic resolution

413 (Gibson et al. 2014), and previous studies have shown that it is not suitable for determining the

414 species-level richness of environmental samples, which was also found in our study (Tang et al.

415 2012). However, COI is more suitable for taxonomic identification at the species level because it

416 has a higher mutation rate, and its high resolution is usually not achieved by the highly

417 conservative 18S (Dupuis et al. 2012; Tang et al. 2012). Although the resolution of 18S rRNA

418 genes is lower than that of COI at the species level, its resolution is higher than that of COI for

419 taxonomic levels other than the species level. Therefore, when the research is not aimed at the

420 species level, 18S is sufficient. Otherwise, COI is more suitable. We also found that the lower the

421 taxonomic level, the less overlap between the zooplankton taxa identified by the two markers

422 (Wangensteen et al. 2018). In addition, 18S is superior to COI in identifying Protozoa, but the

423 situation is the opposite when identifying rotifers, copepods and cladocerans. It should be noted

424 that the 18S rRNA datasets only identified 2 OTUs of Cladocera, and neither of them were

425 identified at the species level, which is in sharp contrast with the results of COI identification.

426 Amplicon length polymorphisms have been shown to cause differential bias (amplification and

427 taxonomic) in metabarcoding studies of bacteria and fungi (Ihrmark et al. 2012; Ziesemer et al.

428 2015), which may explain why only 2 cladoceran OTUs were detected in 18S. If we used only $18 \mathrm{~S}$

429 to analyze our samples instead of two markers (nuclear and mitochondrial gene), we would have

430 failed to detect the important influence of cladocerans on the observed beta-diversity (Clarke et al. 
431 2017). This finding emphasized the benefits of using multiple markers metabarcoding methods for

432 biodiversity assessment. It also illustrates that the use of a single molecular marker for the

433 taxonomic identification of environmental DNA is limited. Although inconsistent results may

434 occur by using multiple markers in metabarcoding technology (Dupuis et al. 2012), it can

435 maximize the information needed for restoring the biodiversity of the ecosystem.

436 Protozoa, especially ciliates, were the most diverse zooplankton community group, which

437 was consistent with the survey of zooplankton diversity in the Xiangxi River of the Three Gorges

438 Reservoir (Li et al. 2019b). Compared with other zooplankton groups, the protozoan

439 species were dominant, but their relative abundance was low throughout the year,

440 which may be caused by amplification and primer bias. The usefulness of DNA

441 metabarcoding technology for quantitative analysis of species abundance is limited

442 by biological and technical biases, which can affect sequence reads counts (Thomas

443 et al. 2016). The PCR step may introduce chimeric sequences, biasing in taxonomic

444 representation (primer bias) (Bista et al. 2018). Primer-template mismatches can

445 reduce the amplification efficiency, and the resulting bias is further enhanced by the

446 number of PCR cycles (amplification deviation) (Giebner et al. 2020; Piñol et al.

447 2019). Moreover, sequencing bias may also affect the abundance estimation in metabarcoding

448 research (Esling et al. 2015; Lee et al. 2012). Although the read counts of metabarcoding

449 technology are extremely dependent on the amount of DNA as well as the number of gene copies

450 and primer bias (Elbrecht \& Leese 2015), it can provide a preliminary or semi-quantitative 
451

452

453

454

455

456

457

458

459

460

461

462

463

464

465

466

467

468

469

470

estimation of relative abundance (Yang et al. 2017b). While the relative abundance of reads is not an accurate measure of abundance at the community level, we assumed that these biases would not have a significant impact on intra-taxon comparisons between samples, so these data can be used to examine the comparative differences in the identified taxa between different sampling dates (Banerji et al. 2018).

Rotifers have high values of both richness and relative abundance because they are $r$ strategists, or opportunists with a small size and short life cycle, and they are tolerant to various environmental factors; thus, rotifers were dominant in the reservoir environment (Neves et al. 2003; Nogueira 2001). Moreover, the phenotypic plasticity and strong applicability masticatory apparatus of Rotifera also created favorable conditions for its success (Segers 2007). A large number of studies showed that Rotifera can be used as indicators of water nutrition status, where the presence of Brachionus indicates that water bodies are at moderate to high levels of organic pollution (Sládeček 1983; Whitman et al. 2004). In our study, Brachionus was found in all zooplankton samples with high diversity, which shows that the water in the reservoir was in a medium or high trophic state. Of course, other genera (Keratella and Rotaria) used to indicate eutrophication status were also found in this study (Mageed 2007; Tackx et al. 2004). Therefore, it is necessary to strengthen the monitoring of pollution sources in the reservoir area, strictly control the increase of new pollution sources, improve the water quality of the reservoir area, and provide strong support for the sustainable development of water ecology in the reservoir area (Liang et al. 2015)

Peer) reviewing PDF | (2020:06:49993:3:0:NEW 4 Feb 2021) 


\section{Seasonal changes in the zooplankton community}

472 Metabarcoding technology can also detect distinct seasonal patterns of taxa that are generally not

473 detectable using traditional methods (Banerji et al. 2018). The analysis shows that the zooplankton

474 community has obvious seasonal changes in Sanmenxia Reservoir. This finding is consistent with

475 previous studies of significant seasonal changes in the zooplankton community based on

476 traditional morphological monitoring and metabarcoding techniques in other freshwater reservoirs

477 (Mwagona et al. 2018; Nandini et al. 2008; Tan et al. 2004; Vanderploeg et al. 2012) However,

478 the relative abundance identified for Cladocera did not differ significantly between seasons despite

479 its relative abundance in COI being significantly higher than that in $18 \mathrm{~S}$. According to reports, the

480 seasonal changes in Cladocera were controlled by the seasonal changes in nutrients (Xiao-Jun et

481 al. 2014). We found that the seasonal variation in TP was not large in our study, which explains

482 the nonsignificant seasonal variation in Cladocera. Biodiversity patterns were strongly structured

483 temporally, which was reflected in alpha- and beta-diversity measures (Banerji et al. 2018).Their

484 change patterns throughout seasons indicated that zooplankton responded to changes in the water

485 environment of the reservoir. Moreover, when we explored the seasonal variation pattern, we

486 found similar beta-diversity in the two markers, which was consistent with the findings of Clarke

487 et al.(Clarke et al. 2017).

488 Effects of water environmental factors

489 Water environmental factors can directly or indirectly affect the zooplankton community. In this 
490

491

492

493

494

495

496

497

498

499

500

501

502

503

504

505

506

507

508

509

study, we found that WT, COD, TN and ammonia nitrogen were the main water environmental

factors driving seasonal changes in the richness of the zooplankton community, and six water environmental factors other than dissolved oxygen had important effects on the relative abundance of zooplankton. We also found that WT was the most powerful environmental factor driving the seasonal changes in zooplankton (partial Mantel test, Adonis, $p<0.01$ ) (Sellami et al. 2016; Sunagawa et al. 2015), followed by TN. This result confirmed that temperature and nutrient accumulation were the most important water environmental factors that affected the seasonal changes in the zooplankton community (Li et al. 2019a). Different zooplankton species have specific optimal temperatures ( $\mathrm{Li}$ et al. 2019a). Appropriate temperature conditions promote the growth and predation of some zooplankton groups, resulting in seasonal changes in zooplankton groups.

Some important variables (chlorophyll a, phytoplankton biomass, particulate organic carbon, precipitation) were not monitored, although we tested multiple water environmental factors. These factors may also have significant effects on the zooplankton community structure, but they exceeded the scope of this study. In addition, it has been observed that climate change and fishery pressure can also cause changes in the populations and composition of zooplankton in aquatic ecosystems around the world (Richardson 2008; Sarma et al. 2005). Unfortunately, understanding these factors is beyond the scope of this study because of the lack of relevant data on climate change, fish farming, and predation in the Sanmenxia Reservoir. 
510 biodiversity research (Deiner et al. 2017; Lim et al. 2016), many technical issues have not been

511 resolved or properly resolved (Xiong et al. 2016a; Xiong et al. 2016b). A large number of studies

512 have extensively discussed the ways in which some technical biases related to DNA extraction,

513 PCR conditions, primer specificity, library preparation and sequence analysis could affect the

514 analysis results (Esling et al. 2015; Kermarrec et al. 2013; Lee et al. 2012). Therefore, there is still

515 a great need for a complete and standardized protocol (Majaneva et al. 2018). In addition, the gaps

516 and misidentifications in the reference database can cause obstacles to the assignment of taxonomy

517 to environmental sequences (Visco et al. 2015). Considering the advantages and limitations

518 of DNA metabarcoding technology, we propose using both $18 \mathrm{~S}$ and COI as markers to reveal

519 the breadth of zooplankton diversity in the Sanmenxia Reservoir to overcome the inherent

520 limitations of using a single marker.

522 CONCLUSION

523 Zooplankton communities show obvious seasonal variations in the Sanmenxia Reservoir.

524 Temperature and nutrients are the most important water environmental factors affecting the

525 seasonal changes in zooplankton communities. The results of this study provide data support for

526 aquatic biodiversity protection in the Sanmenxia Reservoir and for sustainable ecological

527 management. 


\section{ACKNOWLEDGEMENTS}

530 We thank Yingchun Lu for assisting us in sample collection, Hao Yuan, Xiaopeng Wang,

531 Yuanquan Luo and Houyun Huang for our help in data analysis, and Xiaolei Feng for improving

532 the language of the manuscript. 
534

535

536

537

538

539

540

541

542

543

544

545

546

547

548

549

550

551

552

553

554

555

556

557

558

559

560

561

562

563

564

565

\section{References}

Abell R, Thieme ML, Revenga C, Bryer M, Kottelat M, Bogutskaya N, Coad B, Mandrak N, Balderas SC, and Bussing W. 2008. Freshwater ecoregions of the world: a new map of biogeographic units for freshwater biodiversity conservation. BioScience 58:403-414.

Allan JD. 1976. Life history patterns in zooplankton. The American Naturalist 110:165-180.

Altschul SF, Gish W, Miller W, Myers EW, and Lipman DJ. 1990. Basic local alignment search tool. Journal of molecular biology 215:403-410.

Amaral-Zettler LA, McCliment EA, Ducklow HW, and Huse SM. 2009. A method for studying protistan diversity using massively parallel sequencing of V9 hypervariable regions of small-subunit ribosomal RNA genes. PLoS One 4.

Anderson MJ. 2001. A new method for non-parametric multivariate analysis of variance. Austral ecology 26:32-46.

Banerji A, Bagley M, Elk M, Pilgrim E, Martinson J, and Santo Domingo J. 2018. Spatial and temporal dynamics of a freshwater eukaryotic plankton community revealed via 18S rRNA gene metabarcoding. Hydrobiologia 818:71-86.

Banse K. 1995. Zooplankton: pivotal role in the control of ocean production: I. Biomass and production. ICES Journal of Marine Science 52:265-277.

Beng KC, Tomlinson KW, Shen XH, Surget-Groba Y, Hughes AC, Corlett RT, and Slik JF. 2016. The utility of DNA metabarcoding for studying the response of arthropod diversity and composition to land-use change in the tropics. Scientific reports 6:1-13.

Berry TE, Saunders BJ, Coghlan ML, Stat M, Jarman S, Richardson AJ, Davies CH, Berry O, Harvey ES, and Bunce M. 2019. Marine environmental DNA biomonitoring reveals seasonal patterns in biodiversity and identifies ecosystem responses to anomalous climatic events. PLoS genetics 15.

Bista I, Carvalho GR, Tang M, Walsh K, Zhou X, Hajibabaei M, Shokralla S, Seymour M, Bradley D, and Liu S. 2018. Performance of amplicon and shotgun sequencing for accurate biomass estimation in invertebrate community samples. Molecular ecology resources 18:1020-1034.

Bolger AM, Lohse M, and Usadel B. 2014. Trimmomatic: a flexible trimmer for Illumina sequence data. Bioinformatics 30:2114-2120.

Branco CW, Rocha MIA, Pinto GF, Gômara GA, and Filippo RD. 2002. Limnological features of Funil Reservoir (RJ, Brazil) and indicator properties of rotifers and cladocerans of the zooplankton community. Lakes \& Reservoirs: Research \& Management 7:87-92.

Bucklin A, Lindeque PK, Rodriguez-Ezpeleta N, Albaina A, and Lehtiniemi M. 2016. Metabarcoding of marine zooplankton: prospects, progress and pitfalls. Journal of Plankton Research 38:393-400.

Peer] reviewing PDF | (2020:06:49993:3:0:NEW 4 Feb 2021) 
566

567

568

569

570

571

572

573

574

575

576

577

578

579

580

581

582

583

584

585

586

587

588

589

590

591

592

593

594

595

596

597

598

599

600

Bucklin A, Yeh HD, Questel JM, Richardson DE, Reese B, Copley NJ, and Wiebe PH. 2019. Time-series metabarcoding analysis of zooplankton diversity of the NW Atlantic continental shelf. ICES Journal of Marine Science 76:1162-1176.

Chain FJ, Brown EA, MacIsaac HJ, and Cristescu ME. 2016. Metabarcoding reveals strong spatial structure and temporal turnover of zooplankton communities among marine and freshwater ports. Diversity and Distributions 22:493-504.

Chen J, Zhou W, Han S, and Sun G. 2017. Influences of retrogressive erosion of reservoir on sedimentation of its downstream river channel-A case study on Sanmenxia Reservoir and the Lower Yellow River. International Journal of Sediment Research 32:373-383.

Clarke LJ, Beard JM, Swadling KM, and Deagle BE. 2017. Effect of marker choice and thermal cycling protocol on zooplankton DNA metabarcoding studies. Ecology and Evolution 7:873-883.

Creer S, Deiner K, Frey S, Porazinska D, Taberlet P, Thomas WK, Potter C, and Bik HM. 2016. The ecologist's field guide to sequence-based identification of biodiversity. Methods in Ecology and Evolution 7:10081018.

Deiner K, Bik HM, Mächler E, Seymour M, Lacoursière-Roussel A, Altermatt F, Creer S, Bista I, Lodge DM, and De Vere N. 2017. Environmental DNA metabarcoding: Transforming how we survey animal and plant communities. Molecular ecology 26:5872-5895.

Djurhuus A, Pitz K, Sawaya NA, Rojas-Marquez J, Michaud B, Montes E, Muller-Karger F, and Breitbart M. 2018. Evaluation of marine zooplankton community structure through environmental DNA metabarcoding. Limnol Oceanogr Methods 16:209-221. 10.1002/lom3.10237

Drummond AJ, Newcomb RD, Buckley TR, Xie D, Dopheide A, Potter BC, Heled J, Ross HA, Tooman L, and Grosser S. 2015. Evaluating a multigene environmental DNA approach for biodiversity assessment. Gigascience 4:s13742-13015-10086-13741.

Dudgeon D, Arthington AH, Gessner MO, Kawabata Z-I, Knowler DJ, Lévêque C, Naiman RJ, Prieur-Richard A-H, Soto D, and Stiassny ML. 2006. Freshwater biodiversity: importance, threats, status and conservation challenges. Biological reviews 81:163-182.

Dupuis JR, Roe AD, and Sperling FA. 2012. Multi-locus species delimitation in closely related animals and fungi: one marker is not enough. Molecular ecology 21:4422-4436.

Edgar RC. 2013. UPARSE: highly accurate OTU sequences from microbial amplicon reads. Nature methods 10:996.

Edgar RC, Haas BJ, Clemente JC, Quince C, and Knight R. 2011. UCHIME improves sensitivity and speed of chimera detection. Bioinformatics 27:2194-2200.

Elbrecht V, and Leese F. 2015. Can DNA-based ecosystem assessments quantify species abundance? Testing primer bias and biomass - sequence relationships with an innovative metabarcoding protocol. PLoS One 10:e130324.

Peer) reviewing PDF | (2020:06:49993:3:0:NEW 4 Feb 2021) 
601

602

603

604

605

606

607

608

609

610

611

612

613

614

615

616

617

618

619

620

621

622

623

624

625

626

627

628

629

630

631

632

633

Engelbrektson A, Kunin V, Wrighton KC, Zvenigorodsky N, Chen F, Ochman H, and Hugenholtz P. 2010. Experimental factors affecting PCR-based estimates of microbial species richness and evenness. The ISME journal 4:642-647.

Esling P, Lejzerowicz F, and Pawlowski J. 2015. Accurate multiplexing and filtering for high-throughput ampliconsequencing. Nucleic acids research 43:2513-2524.

Fernando CH. 2002. A guide to tropical freshwater zooplankton: identification, ecology and impact on fisheries: Backhuys Publishers.

Friedl G, and Wüest A. 2002. Disrupting biogeochemical cycles-Consequences of damming. Aquatic Sciences 64:55-65.

Gannon JE, and Stemberger RS. 1978. Zooplankton (especially crustaceans and rotifers) as indicators of water quality. Transactions of the American Microscopical Society:16-35.

Gao Y, Yang Q, Li H, Wang X, and Zhan A. 2019. Anthropogenic pollutant-driven geographical distribution of mesozooplankton communities in estuarine areas of the Bohai Sea, China. Scientific reports 9:1-12.

Geller J, Meyer C, Parker M, and Hawk H. 2013. Redesign of PCR primers for mitochondrial cytochrome c oxidase subunit I for marine invertebrates and application in all-taxa biotic surveys. Molecular ecology resources 13:851-861.

Gibson J, Shokralla S, Porter TM, King I, van Konynenburg S, Janzen DH, Hallwachs W, and Hajibabaei M. 2014. Simultaneous assessment of the macrobiome and microbiome in a bulk sample of tropical arthropods through DNA metasystematics. Proceedings of the National Academy of Sciences 111:8007-8012.

Giebner H, Langen K, Bourlat SJ, Kukowka S, Mayer C, Astrin JJ, Misof B, and Fonseca VG. 2020. Comparing diversity levels in environmental samples: DNA sequence capture and metabarcoding approaches using $18 \mathrm{~S}$ and COI genes. Molecular ecology resources.

Hadziavdic K, Lekang K, Lanzen A, Jonassen I, Thompson EM, and Troedsson C. 2014. Characterization of the 18S rRNA gene for designing universal eukaryote specific primers. PLoS One 9:e87624.

Ihrmark K, Bödeker I, Cruz-Martinez K, Friberg H, Kubartova A, Schenck J, Strid Y, Stenlid J, Brandström-Durling M, and Clemmensen KE. 2012. New primers to amplify the fungal ITS2 region-evaluation by 454sequencing of artificial and natural communities. FEMS microbiology ecology 82:666-677.

Ji Y, Ashton L, Pedley SM, Edwards DP, Tang Y, Nakamura A, Kitching R, Dolman PM, Woodcock P, and Edwards FA. 2013. Reliable, verifiable and efficient monitoring of biodiversity via metabarcoding. Ecology letters 16:1245-1257.

Kermarrec L, Franc A, Rimet F, Chaumeil P, Humbert J-F, and Bouchez A. 2013. Next-generation sequencing to inventory taxonomic diversity in eukaryotic communities: a test for freshwater diatoms. Molecular ecology resources 13:607-619.

Peer) reviewing PDF | (2020:06:49993:3:0:NEW 4 Feb 2021) 
634

635

636

637

638

639

640

641

642

643

644

645

646

647

648

649

650

651

652

653

654

655

656

657

658

659

660

661

662

663

664

665

666

667

Lee CK, Herbold CW, Polson SW, Wommack KE, Williamson SJ, McDonald IR, and Cary SC. 2012.

Groundtruthing next-gen sequencing for microbial ecology-biases and errors in community structure estimates from PCR amplicon pyrosequencing. PLoS One 7:e44224.

Leray M, and Knowlton N. 2015. DNA barcoding and metabarcoding of standardized samples reveal patterns of marine benthic diversity. Proceedings of the National Academy of Sciences 112:2076-2081.

Li C, Feng W, Chen H, Li X, Song F, Guo W, Giesy JP, and Sun F. 2019a. Temporal variation in zooplankton and phytoplankton community species composition and the affecting factors in Lake Taihu—a large freshwater lake in China. Environmental pollution 245:1050-1057.

Li X, Huang J, Filker S, Stoeck T, Bi Y, Yu Y, and Song W. 2019b. Spatio-temporal patterns of zooplankton in a main-stem dam affected tributary: a case study in the Xiangxi River of the Three Gorges Reservoir, China. Science China Life Sciences 62:1058-1069.

Liang W, Dong-Sheng C, Chang L, Zhan-Po M, and Shi-Yan W. 2015. The Variation Process and the Key Influencing Factors of Water Quality in Sanmenxia Reservoir. China Rural Water and Hydropower.

Lim NK, Tay YC, Srivathsan A, Tan JW, Kwik JT, Baloğlu B, Meier R, and Yeo DC. 2016. Next-generation freshwater bioassessment: eDNA metabarcoding with a conserved metazoan primer reveals species-rich and reservoir-specific communities. Royal Society open science 3:160635.

Lindeque PK, Parry HE, Harmer RA, Somerfield PJ, and Atkinson A. 2013. Next generation sequencing reveals the hidden diversity of zooplankton assemblages. PLoS One 8:e81327. 10.1371/journal.pone.0081327

Lubzens E. 1987. Raising rotifers for use in aquaculture. Rotifer Symposium IV: Springer. p 245-255.

Maavara T, Lauerwald R, Regnier P, and Van Cappellen P. 2017. Global perturbation of organic carbon cycling by river damming. Nature communications 8:1-10.

Machida RJ, Hashiguchi Y, Nishida M, and Nishida S. 2009. Zooplankton diversity analysis through single-gene sequencing of a community sample. BMC Genomics 10:438.

Mageed AAA. 2007. Distribution and long-term historical changes of zooplankton assemblages in Lake Manzala (south Mediterranean Sea, Egypt).

Magoč T, and Salzberg SL. 2011. FLASH: fast length adjustment of short reads to improve genome assemblies. Bioinformatics 27:2957-2963.

Majaneva M, Diserud OH, Eagle SH, Boström E, Hajibabaei M, and Ekrem T. 2018. Environmental DNA filtration techniques affect recovered biodiversity. Scientific reports 8:1-11.

Martin M. 2011. Cutadapt removes adapter sequences from high-throughput sequencing reads. EMBnet journal 17:10-12.

Mwagona PC, Chengxue M, and Hongxian Y. 2018. Seasonal dynamics of Zooplankton functional groups in relation to environmental variables in Xiquanyan Reservoir, Northeast China. Annales de LimnologieInternational Journal of Limnology: EDP Sciences. p 33.

Peer) reviewing PDF | (2020:06:49993:3:0:NEW 4 Feb 2021) 
668

669

670

671

672

673

674

675

676

677

678

679

680

681

682

683

684

685

686

687

688

689

690

691

692

693

694

695

696

697

698

699

700

Nandini S, Merino-Ibarra M, and Sarma S. 2008. Seasonal changes in the zooplankton abundances of the reservoir Valle de Bravo (State of Mexico, Mexico). Lake and Reservoir Management 24:321-330.

Neves I, Rocha O, Roche K, and Pinto A. 2003. Zooplankton community structure of two marginal lakes of the river Cuiabá (Mato Grosso, Brazil) with analysis of Rotifera and Cladocera diversity. Brazilian Journal of Biology 63:329-343.

Nogueira MG. 2001. Zooplankton composition, dominance and abundance as indicators of environmental compartmentalization in Jurumirim Reservoir (Paranapanema River), São Paulo, Brazil. Hydrobiologia 455:1-18.

Nolte V, Pandey RV, Jost S, Medinger R, Ottenwaelder B, Boenigk J, and Schloetterer C. 2010. Contrasting seasonal niche separation between rare and abundant taxa conceals the extent of protist diversity. Molecular ecology 19:2908-2915.

Oh H-J, Jeong H-G, Nam G-S, Oda Y, Dai W, Lee E-H, Kong D, Hwang S-J, and Chang K-H. 2017. Comparison of taxon-based and trophi-based response patterns of rotifer community to water quality: applicability of the rotifer functional group as an indicator of water quality. Animal cells and systems 21:133-140.

Oksanen J, Blanchet FG, Kindt R, Legendre P, O’hara R, Simpson GL, Solymos P, Stevens MHH, and Wagner H. 2010. Vegan: community ecology package. R package version 1.17-4. URL http://CRAN R-project org/package= vegan .

Pace ML, and Orcutt Jr JD. 1981. The relative importance of protozoans, rotifers, and crustaceans in a freshwater zooplankton community 1. Limnology and Oceanography 26:822-830.

Pawlowski J, Lejzerowicz F, Apotheloz-Perret-Gentil L, Visco J, and Esling P. 2016. Protist metabarcoding and environmental biomonitoring: time for change. European Journal of Protistology 55:12-25.

Pimm SL, Jenkins CN, Abell R, Brooks TM, Gittleman JL, Joppa LN, Raven PH, Roberts CM, and Sexton JO. 2014. The biodiversity of species and their rates of extinction, distribution, and protection. Science 344:1246752.

Piñol J, Senar MA, and Symondson WO. 2019. The choice of universal primers and the characteristics of the species mixture determine when DNA metabarcoding can be quantitative. Molecular ecology 28:407-419.

Pruesse E, Quast C, Knittel K, Fuchs BM, Ludwig W, Peplies J, and Glöckner FO. 2007. SILVA: a comprehensive online resource for quality checked and aligned ribosomal RNA sequence data compatible with ARB. Nucleic acids research 35:7188-7196.

Qiaoyu G, and Zhifeng Y. 2005. Post-project ecological analysis for the Sanmenxia Dam. Acta Scientiae Circumstantiae 25:580-585.

Ratnasingham S, and Hebert PD. 2007. BOLD: The Barcode of Life Data System (http://www. barcodinglife. org). Molecular ecology notes 7:355-364.

Peer] reviewing PDF | (2020:06:49993:3:0:NEW 4 Feb 2021) 
701

702

703

704

705

706

707

708

709

710

711

712

713

714

715

716

717

718

719

720

721

722

723

724

725

726

727

728

729

730

731

732

733

734

735

Revenga C, Campbell I, Abell R, De Villiers P, and Bryer M. 2005. Prospects for monitoring freshwater ecosystems towards the 2010 targets. Philosophical Transactions of the Royal Society B: Biological Sciences 360:397413.

Ricciardi A, and Rasmussen JB. 1999. Extinction rates of North American freshwater fauna. Conservation biology 13:1220-1222.

Richardson AJ. 2008. In hot water: zooplankton and climate change. ICES Journal of Marine Science 65:279-295.

Sala OE, Chapin FS, Armesto JJ, Berlow E, Bloomfield J, Dirzo R, Huber-Sanwald E, Huenneke LF, Jackson RB, and Kinzig A. 2000. Global biodiversity scenarios for the year 2100. Science 287:1770-1774.

Sarma S, Nandini S, and Gulati R. 2005. Life history strategies of cladocerans: comparisons of tropical and temperate taxa. Aquatic Biodiversity II: Springer, 315-333.

Segers H. 2007. Global diversity of rotifers (Rotifera) in freshwater. Freshwater Animal Diversity Assessment: Springer, 49-59.

Sellami I, Hamza A, El Bour M, Mhamdi MA, Pinelalloul B, and Ayadi H. 2016. Succession of phytoplankton and zooplankton communities coupled to environmental factors in the oligo-mesotrophic Nabhana reservoir (semi arid mediterranean area, central Tunisia). Zoological Studies 55.

Shokralla S, Spall JL, Gibson JF, and Hajibabaei M. 2012. Next-generation sequencing technologies for environmental DNA research. Molecular ecology 21:1794-1805.

Sládeček V. 1983. Rotifers as indicators of water quality. Hydrobiologia 100:169-201.

Sunagawa S, Coelho LP, Chaffron S, Kultima JR, Labadie K, Salazar G, Djahanschiri B, Zeller G, Mende DR, and Alberti A. 2015. Structure and function of the global ocean microbiome. Science 348.

Sundermann A, Haase P, Clarke R, Pauls S, Lohse S, Gunn R, and Sporka F. 2005. Assessing the impact of sorting and identification errors of macroinvertebrate samples.

Tackx ML, De Pauw N, Van Mieghem R, Azémar F, Hannouti A, Van Damme S, Fiers F, Daro N, and Meire P. 2004. Zooplankton in the Schelde estuary, Belgium and The Netherlands. Spatial and temporal patterns. Journal of Plankton Research 26:133-141.

Tan Y, Huang L, Chen Q, and Huang X. 2004. Seasonal variation in zooplankton composition and grazing impact on phytoplankton standing stock in the Pearl River Estuary, China. Continental Shelf Research 24:19491968.

Tang CQ, Leasi F, Obertegger U, Kieneke A, Barraclough TG, and Fontaneto D. 2012. The widely used small subunit $18 \mathrm{~S}$ rDNA molecule greatly underestimates true diversity in biodiversity surveys of the meiofauna. Proceedings of the National Academy of Sciences 109:16208-16212.

Team RC. 2013. R: A language and environment for statistical computing.

Thomas AC, Deagle BE, Eveson JP, Harsch CH, and Trites AW. 2016. Quantitative DNA metabarcoding: improved estimates of species proportional biomass using correction factors derived from control material. Molecular ecology resources 16:714-726.

Peer] reviewing PDF | (2020:06:49993:3:0:NEW 4 Feb 2021) 
736

737

738

739

740

741

742

743

744

745

746

747

748

749

750

751

752

753

754

755

756

757

758

759

760

761

762

763

764

765

766

767

768

769

770

Trebitz AS, Hoffman JC, Darling JA, Pilgrim EM, Kelly JR, Brown EA, Chadderton WL, Egan SP, Grey EK, and Hashsham SA. 2017. Early detection monitoring for aquatic non-indigenous species: Optimizing surveillance, incorporating advanced technologies, and identifying research needs. Journal of environmental management 202:299-310.

Vanderploeg HA, Pothoven SA, Fahnenstiel GL, Cavaletto JF, Liebig JR, Stow CA, Nalepa TF, Madenjian CP, and Bunnell DB. 2012. Seasonal zooplankton dynamics in Lake Michigan: disentangling impacts of resource limitation, ecosystem engineering, and predation during a critical ecosystem transition. Journal of Great Lakes Research 38:336-352.

Visco JA, Apothéloz-Perret-Gentil L, Cordonier A, Esling P, Pillet L, and Pawlowski J. 2015. Environmental monitoring: inferring the diatom index from next-generation sequencing data. Environmental science \& technology 49:7597-7605.

Vörösmarty CJ, McIntyre PB, Gessner MO, Dudgeon D, Prusevich A, Green P, Glidden S, Bunn SE, Sullivan CA, and Liermann CR. 2010. Global threats to human water security and river biodiversity. Nature 467:555561.

Wang G, Wu B, and Wang ZY. 2005. Sedimentation problems and management strategies of sanmenxia reservoir, yellow river, china. Water Resources Research 41.

Wangensteen OS, Palacín C, Guardiola M, and Turon X. 2018. DNA metabarcoding of littoral hard-bottom communities: high diversity and database gaps revealed by two molecular markers. PeerJ 6:e4705.

Whitman RL, Nevers MB, Goodrich ML, Murphy PC, and Davis BM. 2004. Characterization of Lake Michigan coastal lakes using zooplankton assemblages. Ecological Indicators 4:277-286.

Xiao-Jun Z, Bo-Ping H, Qiu-Qi L, Ecology DO, and University J. 2014. Seasonal Dynamics of Cladocera in Two Cascading Reservoirs in Southern China. Journal of Hydroecology.

Xie Y, Wang J, Yang J, Giesy JP, Yu H, and Zhang X. 2017. Environmental DNA metabarcoding reveals primary chemical contaminants in freshwater sediments from different land-use types. Chemosphere 172:201-209.

Xiong W, Huang X, Chen Y, Fu R, Du X, Chen X, and Zhan A. 2020. Zooplankton biodiversity monitoring in polluted freshwater ecosystems: A technical review. Environmental Science and Ecotechnology 1:100008.

Xiong W, Li H, and Zhan A. 2016a. Early detection of invasive species in marine ecosystems using high-throughput sequencing: technical challenges and possible solutions. Marine Biology 163:139.

Xiong W, Li J, Chen Y, Shan B, Wang W, and Zhan A. 2016b. Determinants of community structure of zooplankton in heavily polluted river ecosystems. Scientific reports 6:1-11.

Yang J, Zhang X, Xie Y, Song C, Sun J, Zhang Y, Giesy JP, and Yu H. 2017a. Ecogenomics of zooplankton community reveals ecological threshold of ammonia nitrogen. Environmental science \& technology 51:3057-3064.

Yang J, Zhang X, Xie Y, Song C, Zhang Y, Yu H, and Burton GA. 2017b. Zooplankton community profiling in a eutrophic freshwater ecosystem-lake tai basin by DNA metabarcoding. Scientific reports 7:1-11.

Peer) reviewing PDF | (2020:06:49993:3:0:NEW 4 Feb 2021) 
771 Yang X, and Lu X. 2014. Drastic change in China's lakes and reservoirs over the past decades. Scientific reports

772

773 4:1-10.

Zhang GK, Chain FJ, Abbott CL, and Cristescu ME. 2018. Metabarcoding using multiplexed markers increases species detection in complex zooplankton communities. Evolutionary Applications 11:1901-1914.

Zhang J-j, LU P, ZHANG B-q, LI S-1, DONG R-1, ZHANG L, and WANG W-1. 2012. Geese and Ducks in Sanmenxia Reservoir of the Yellow River. Journal of Henan Institute of Education (Natural Science Edition):16.

Ziesemer KA, Mann AE, Sankaranarayanan K, Schroeder H, Ozga AT, Brandt BW, Zaura E, Waters-Rist A, Hoogland M, and Salazar-García DC. 2015. Intrinsic challenges in ancient microbiome reconstruction using 16S rRNA gene amplification. Scientific reports 5:16498. 


\section{Table 1 (on next page)}

Alpha diversity of the entire zooplankton assemblages in each sample. 


\begin{tabular}{|c|c|c|c|c|c|c|c|c|}
\hline \multirow{2}{*}{ Samples } & \multicolumn{4}{|c|}{$18 S$} & \multicolumn{4}{|c|}{ COI } \\
\hline & OTUs & reads & Shannon & ACE & OTUs & reads & Shannon & ACE \\
\hline SUM_1 & 101 & 31787 & 1.73 & 110.83 & 130 & 22340 & 2.6 & 155.41 \\
\hline SUM_2 & 142 & 58326 & 2.1 & 160.11 & 139 & 22131 & 2.76 & 156.38 \\
\hline SUM_3 & 144 & 56263 & 1.95 & 170.04 & 135 & 21489 & 3.08 & 141.1 \\
\hline SUM_4 & 131 & 42619 & 2.23 & 143.83 & 145 & 20755 & 2.85 & 169.79 \\
\hline SUM_5 & 145 & 87908 & 2.16 & 174.61 & 119 & 21384 & 2.58 & 137.52 \\
\hline SUM_6 & 148 & 84124 & 2.27 & 179.04 & 122 & 21456 & 2.62 & 147.47 \\
\hline SUM_7 & 81 & 48914 & 1.45 & 92.75 & 136 & 19656 & 2.58 & 164.43 \\
\hline SUM_8 & 99 & 34553 & 1.59 & 118.58 & 98 & 18675 & 2.34 & 115.29 \\
\hline SUM_9 & 104 & 51766 & 1.57 & 123.03 & 96 & 18814 & 2.3 & 110.99 \\
\hline AUT_1 & 123 & 30108 & 1.67 & 168.92 & 112 & 5882 & 2.81 & 140.85 \\
\hline AUT_2 & 106 & 18216 & 1.54 & 136.19 & 116 & 3695 & 2.87 & 138.27 \\
\hline AUT_3 & 104 & 27958 & 1.19 & 129.64 & 112 & 5316 & 2.83 & 131.47 \\
\hline AUT_4 & 103 & 34195 & 1.81 & 140.86 & 120 & 9537 & 2.85 & 164.59 \\
\hline AUT_5 & 117 & 44036 & 1.48 & 162.35 & 101 & 4024 & 2.72 & 133.37 \\
\hline AUT_6 & 80 & 26275 & 2.08 & 98.48 & 146 & 8723 & 3.09 & 181.54 \\
\hline AUT_7 & 71 & 52425 & 1.64 & 85.9 & 118 & 14766 & 2.85 & 153.54 \\
\hline AUT_8 & 63 & 69162 & 1.58 & 86.26 & 102 & 19037 & 2.57 & 139.55 \\
\hline AUT_9 & 68 & 66918 & 1.57 & 91.2 & 103 & 16720 & 2.55 & 128.24 \\
\hline WIN_1 & 77 & 31180 & 1.66 & 103.39 & 76 & 17500 & 2.03 & 80.94 \\
\hline WIN_2 & 66 & 16455 & 1.63 & 76.45 & 49 & 2307 & 2.27 & 63.35 \\
\hline WIN_3 & 56 & 11396 & 2.05 & 98.19 & 56 & 4512 & 1.72 & 74.09 \\
\hline WIN_4 & 53 & 71055 & 1.14 & 108.61 & 71 & 21905 & 2.31 & 84.43 \\
\hline WIN_5 & 42 & 55232 & 1.13 & 60.79 & 77 & 21181 & 2.06 & 93.86 \\
\hline
\end{tabular}




\begin{tabular}{|c|c|c|c|c|c|c|c|c|}
\hline WIN_6 & 45 & 28844 & 1.11 & 52.05 & 74 & 21706 & 2.02 & 92.39 \\
\hline WIN_7 & 47 & 8251 & 1.8 & 65.28 & 57 & 2694 & 2.64 & 68.53 \\
\hline WIN_8 & 57 & 8569 & 1.69 & 82.21 & 65 & 6018 & 2.52 & 81.96 \\
\hline WIN_9 & 43 & 12647 & 1.34 & 65.47 & 72 & 5332 & 2.7 & 91 \\
\hline SPR_1 & 40 & 29215 & 0.74 & 60.15 & 66 & 7367 & 1.72 & 78.51 \\
\hline SPR_2 & 32 & 36306 & 0.64 & 34.9 & 59 & 19461 & 1.02 & 67.62 \\
\hline SPR_3 & 43 & 36212 & 0.87 & 85.35 & 79 & 11795 & 2.15 & 97.03 \\
\hline SPR_4 & 31 & 15650 & 1.36 & 50.68 & 87 & 14348 & 2.09 & 114.91 \\
\hline SPR_5 & 41 & 9195 & 1.6 & 69.85 & 78 & 12331 & 1.75 & 86.24 \\
\hline SPR_6 & 26 & 3916 & 1.84 & 35.99 & 79 & 8985 & 2.35 & 82.05 \\
\hline SPR_7 & 39 & 35357 & 0.92 & 46.03 & 68 & 21177 & 1.5 & 99.43 \\
\hline SPR_8 & 87 & 105749 & 0.92 & 113.01 & 85 & 22711 & 1.44 & 114.4 \\
\hline SPR_9 & 83 & 104381 & 1.12 & 111.27 & 93 & 20955 & 1.62 & 131.48 \\
\hline
\end{tabular}




\section{Table 2 (on next page)}

Results of taxonomic assignment of different metabarcoding datasets. 


\begin{tabular}{cccccccc}
\hline & OTUs & Phylum & Class & Order & Family & Genus & Species \\
\hline $18 \mathrm{~S}$ & 319 & 12 & 23 & 54 & 83 & 110 & 84 \\
COI & 395 & 4 & 7 & 19 & 61 & 11 & 80 \\
$18 \mathrm{~S}+\mathrm{COI}$ & $/$ & 12 & 24 & 11 & 174 \\
\hline
\end{tabular}




\section{Table 3 (on next page)}

Water environmental conditions (mean value \pm SE) of Sanmenxia Reservoir. WT, water temperature; $\mathrm{pH}, \mathrm{pH}$; COD, chemical oxygen demand; TP, total phosphorus; NH4-N, ammonium; DO, dissolved oxygen; TN, total nitrogen. 


\begin{tabular}{|c|c|c|c|c|c|c|c|}
\hline Sample & $\mathrm{WT}\left({ }^{\circ} \mathrm{C}\right)$ & $\mathrm{pH}$ & $\mathrm{COD}(\mathrm{mg} / \mathrm{L})$ & $\mathrm{TP}(\mathrm{mg} / \mathrm{L})$ & $\mathrm{NH}_{4}-\mathrm{N}(\mathrm{mg} / \mathrm{L})$ & $\mathrm{DO}(\mathrm{mg} / \mathrm{L})$ & $\mathrm{TN}(\mathrm{mg} / \mathrm{L})$ \\
\hline SUM & $30.41 \pm 0.38$ & $8.11 \pm 0.00$ & $48.73 \pm 3.71$ & $0.04 \pm 0.00$ & $0.45 \pm 0.04$ & $6.97 \pm 0.67$ & $3.90 \pm 0.48$ \\
\hline AUT & $15.97 \pm 0.42$ & $7.68 \pm 0.04$ & $22.98 \pm 1.17$ & $0.02 \pm 0.00$ & $0.20 \pm 0.02$ & $7.77 \pm 0.42$ & $4.79 \pm 0.03$ \\
\hline WIN & $2.67 \pm 0.13$ & $8.10 \pm 0.05$ & $35.50 \pm 3.71$ & $0.07 \pm 0.01$ & $0.79 \pm 0.05$ & $8.31 \pm 0.49$ & $5.05 \pm 0.08$ \\
\hline SPR & $16.66 \pm 1.55$ & $7.81 \pm 0.04$ & $30.56 \pm 1.69$ & $0.05 \pm 0.00$ & $0.23 \pm 0.05$ & $6.16 \pm 0.16$ & $5.30 \pm 0.16$ \\
\hline
\end{tabular}


Figure 1

The number of different taxa recovered by using 18S (blue) or COI (yellow) under different taxonomic levels. (A) Phylum, (B) Class, (C) Order, (D) Family, (E) Genus, (F) species, (G) Protozoa, (H) Rotifera, (I) Copepoda.

A

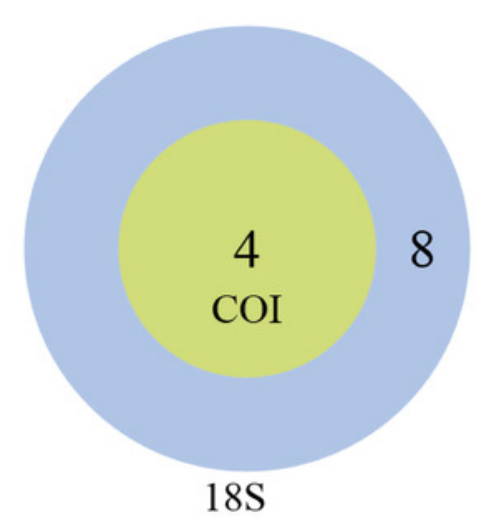

D

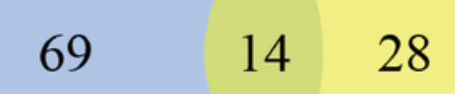

$$
62
$$

$$
220
$$

COI

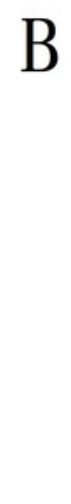

$\mathrm{E}$

E
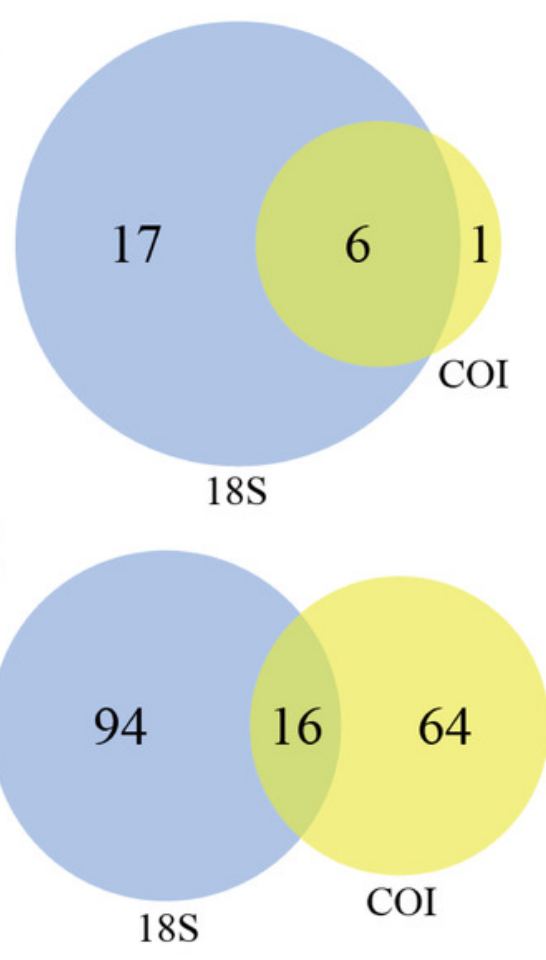

$\mathrm{H}$
$\mathrm{C}$

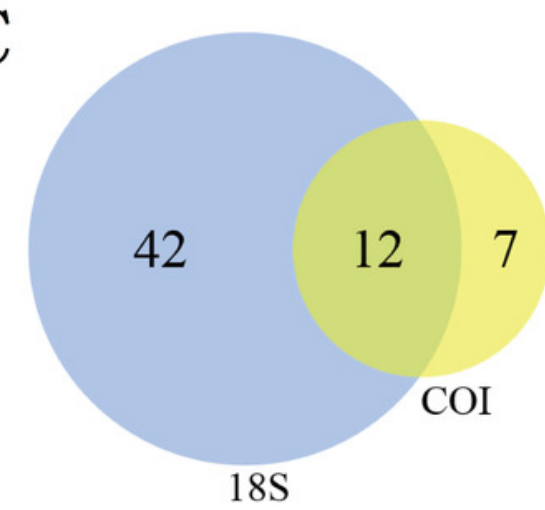

F

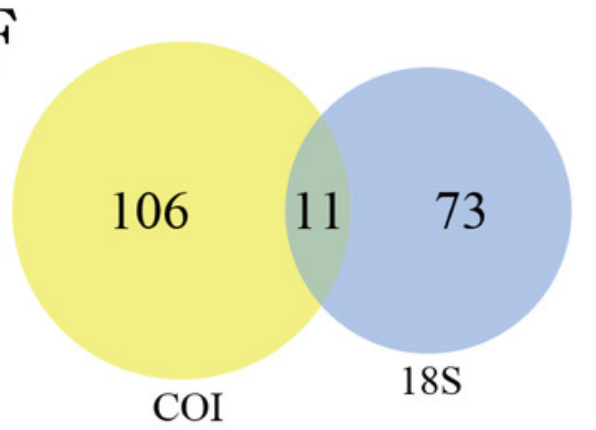

I

25

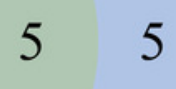


Figure 2

The difference in richness and relative abundance recovered in $18 \mathrm{~S}$ or $\mathrm{COI}$.
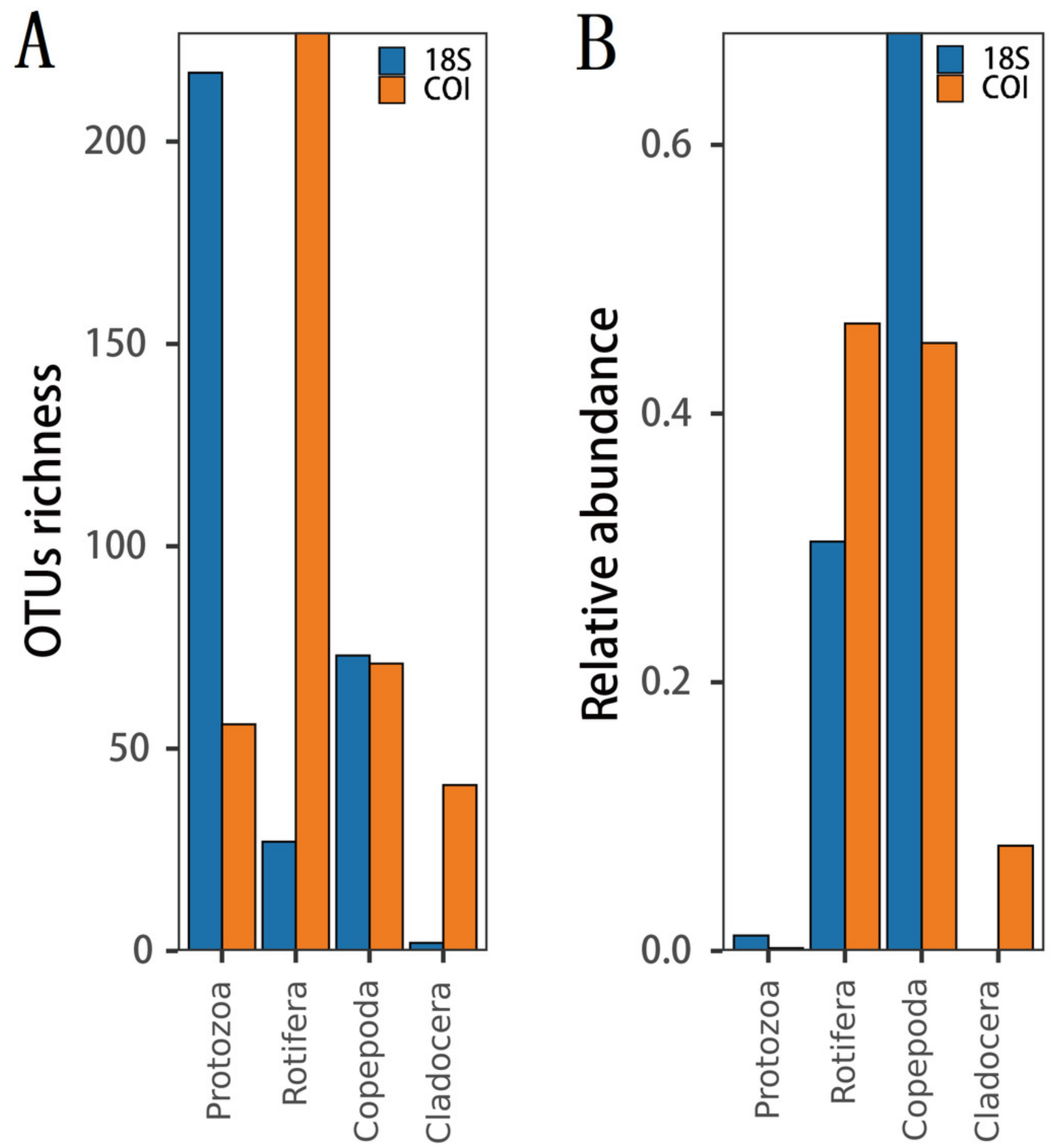
Figure 3

Different diversity estimators show significant differences in seasonal changes in zooplankton community based on different metabarcoding datasets.

(A) 18S Shannon diversity index (B) COI Shannon diversity index, (C) $18 \mathrm{~S}$ ACE index, (D) COI ACE index.

A

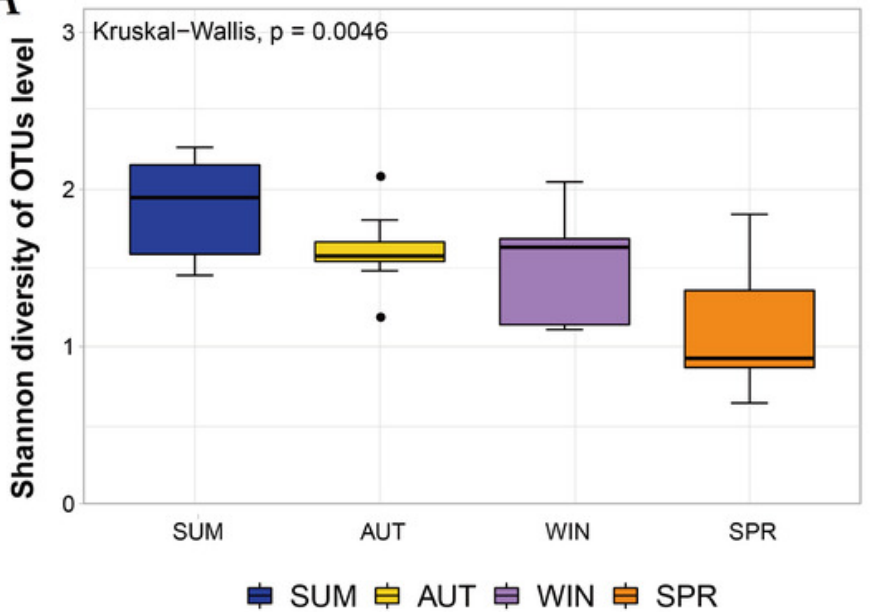

$\mathrm{C}$

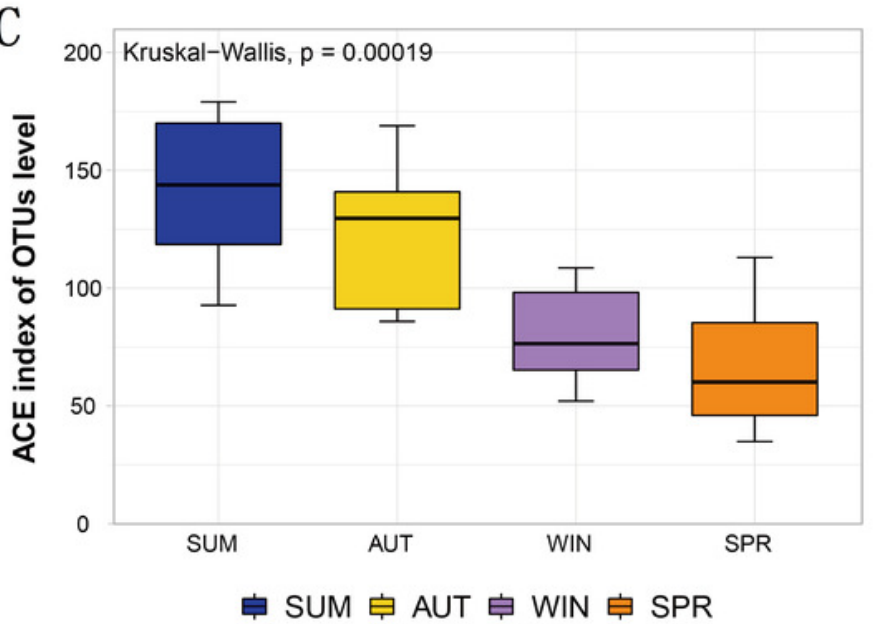

B
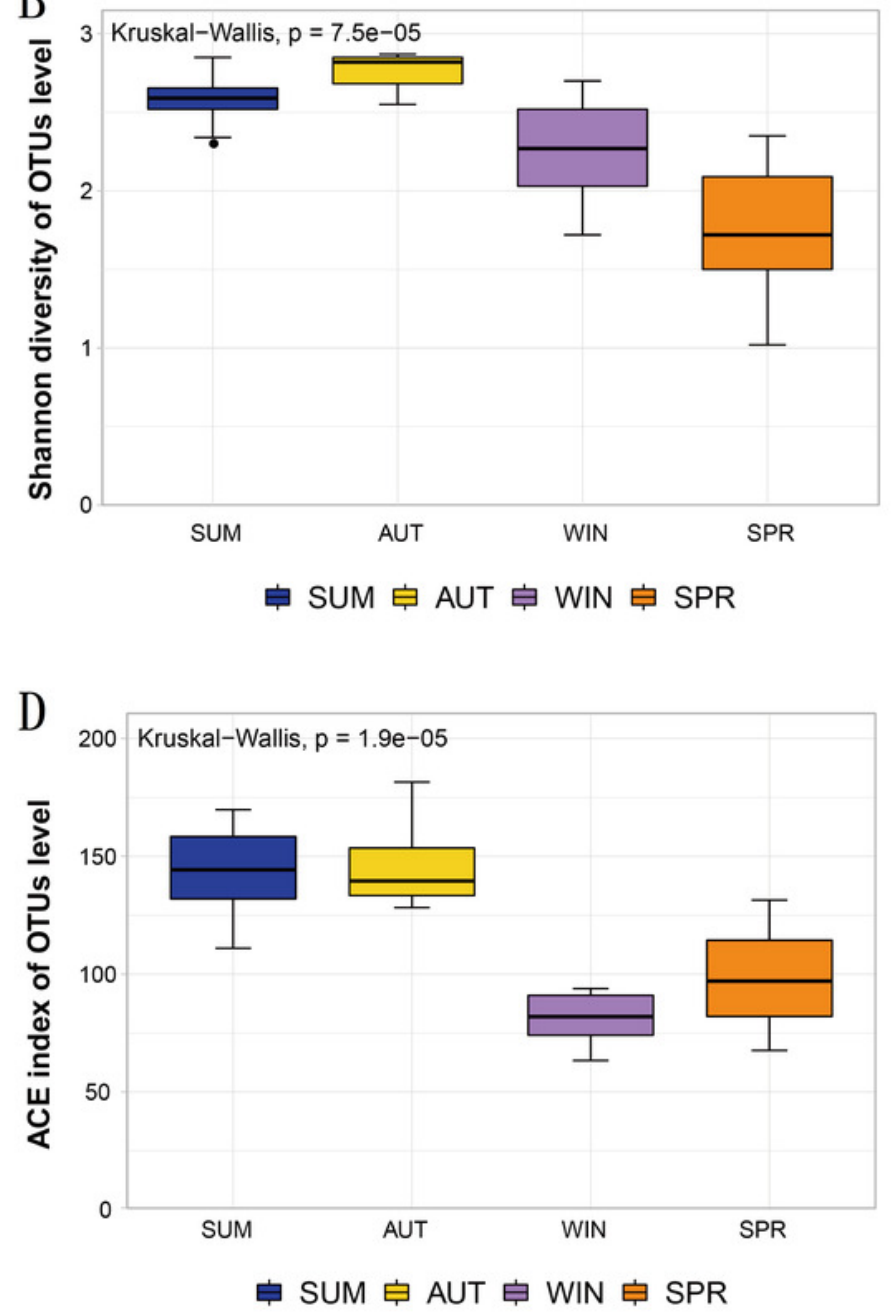


\section{Figure 4}

The richness of zooplankton groups in different seasons shows significant differences based on different metabarcoding datasets.

(A) 18S Protozoa, (B) 18S Rotifera, (C) 18S Copepoda, (D) 18S Cladocera, (E) COI Protozoa, (F) COI Rotifera, (G) COI Copepoda, (H) COI Cladocera. Seasonal changes in zooplankton groups were significant according to ANOVA and multiple comparisons between sampling seasons by using the Tukey HSD test. $*, p \leq 0.05 ; * *, p \leq 0.01 ; * *, p \leq 0.001$. 

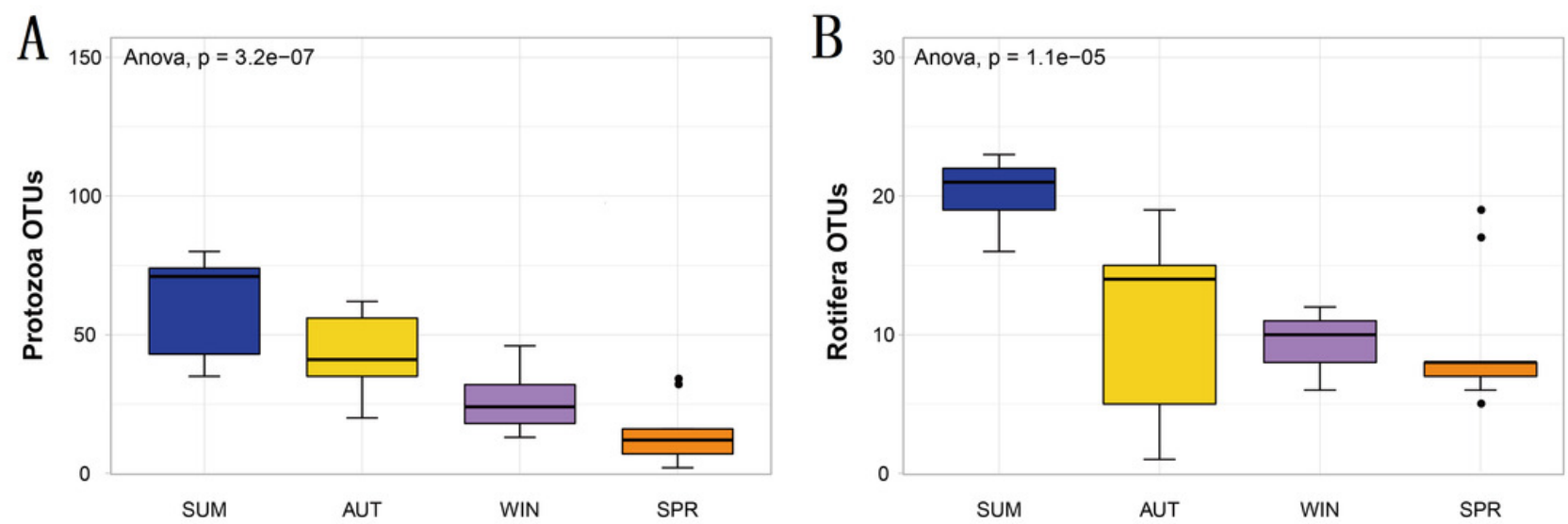

C

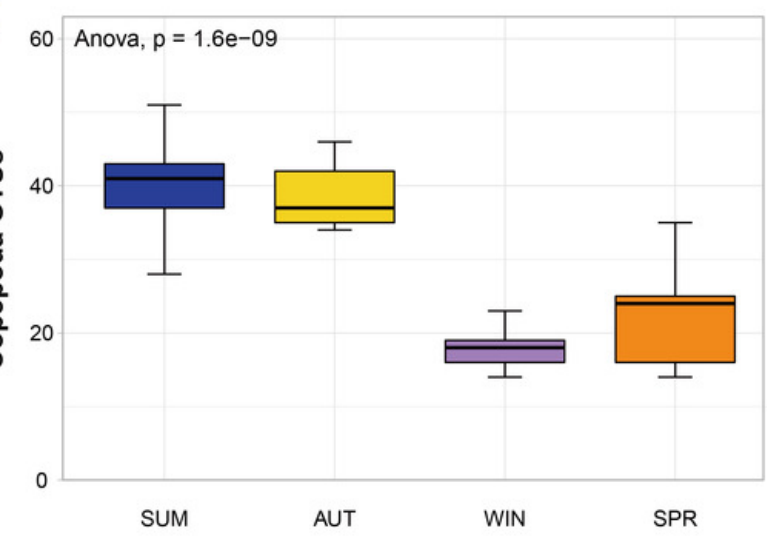

D

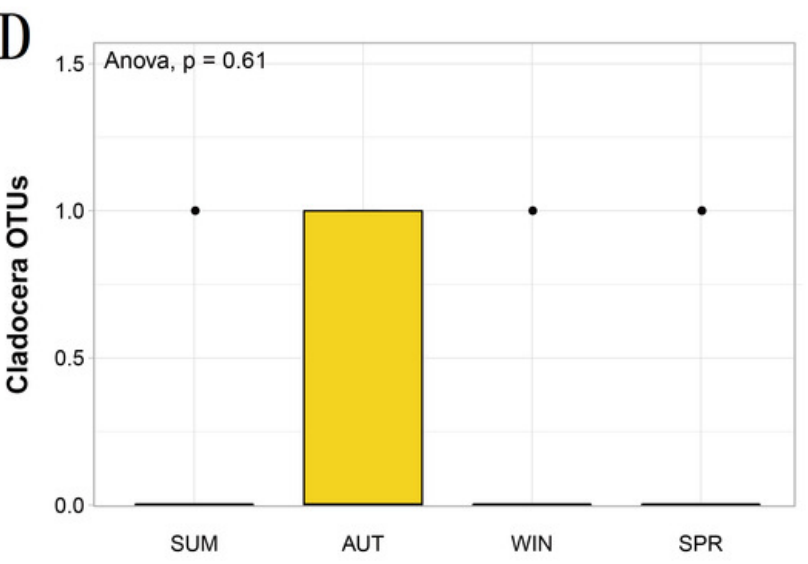

E

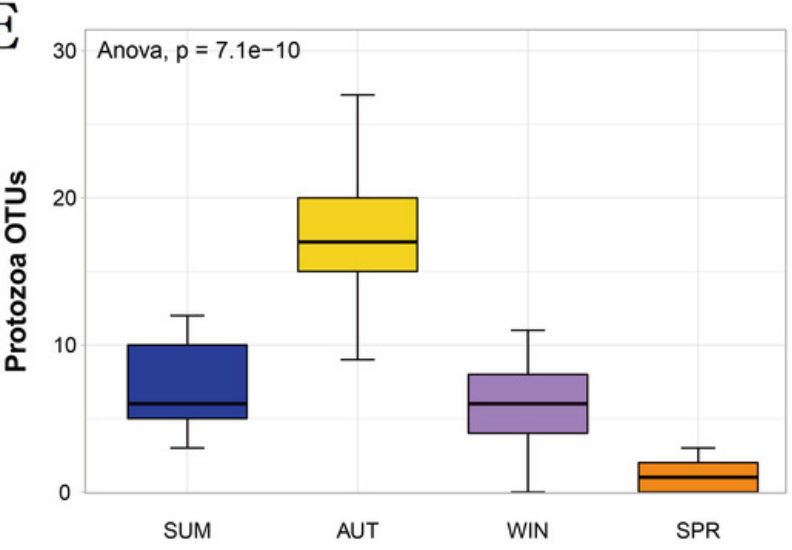

$\mathrm{F}_{100}$ Anova, $\mathrm{p}=1.9 \mathrm{e}-07$

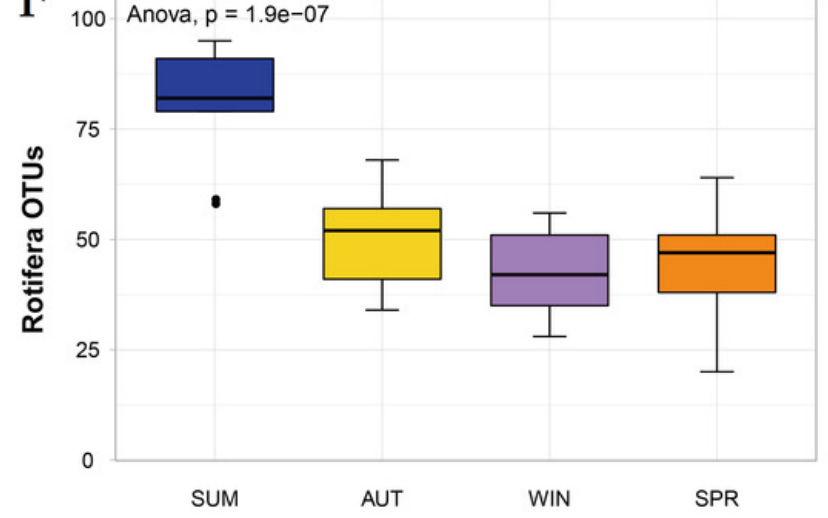

G

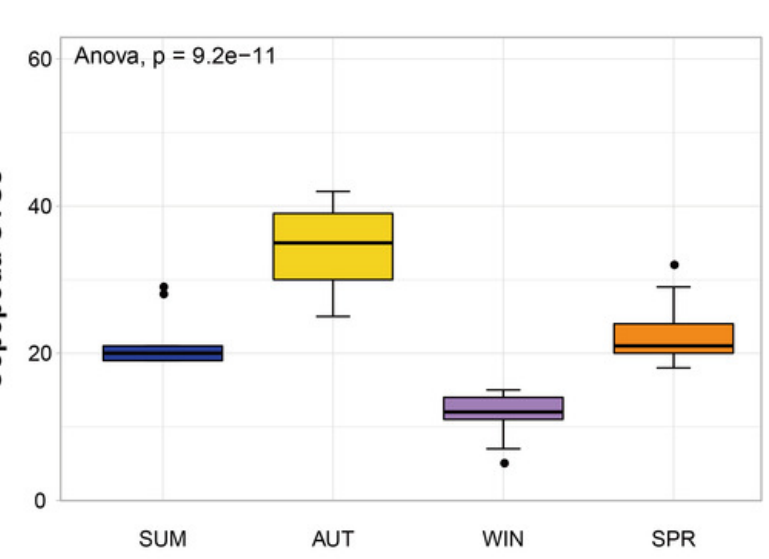

$\mathrm{H}$

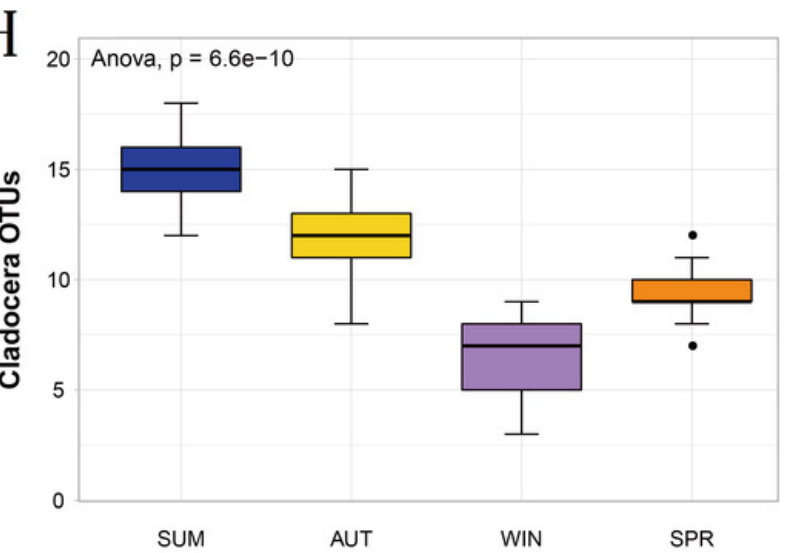


Figure 5

The seasonal variation in relative abundance of different zooplankton groups in different metabarcoding datasets.

(A) $18 \mathrm{~S}$ summer $\&$ autumn, (B) $18 \mathrm{~S}$ autumn $\&$ winter, (C) $18 \mathrm{~S}$ winter $\&$ spring; (D) COI summer $\&$ autumn, (E) COI autumn $\&$ winter, (F) COI winter $\&$ spring. Variations from summer to autumn, autumn to winter and winter to spring are shown. Welch's t-test was used to compare the variation between two adjacent sampling seasons. *, $\mathrm{P} \leq 0.05$; **, $\mathrm{P} \leq 0.01 ; * * *, \mathrm{P} \leq 0.001$.
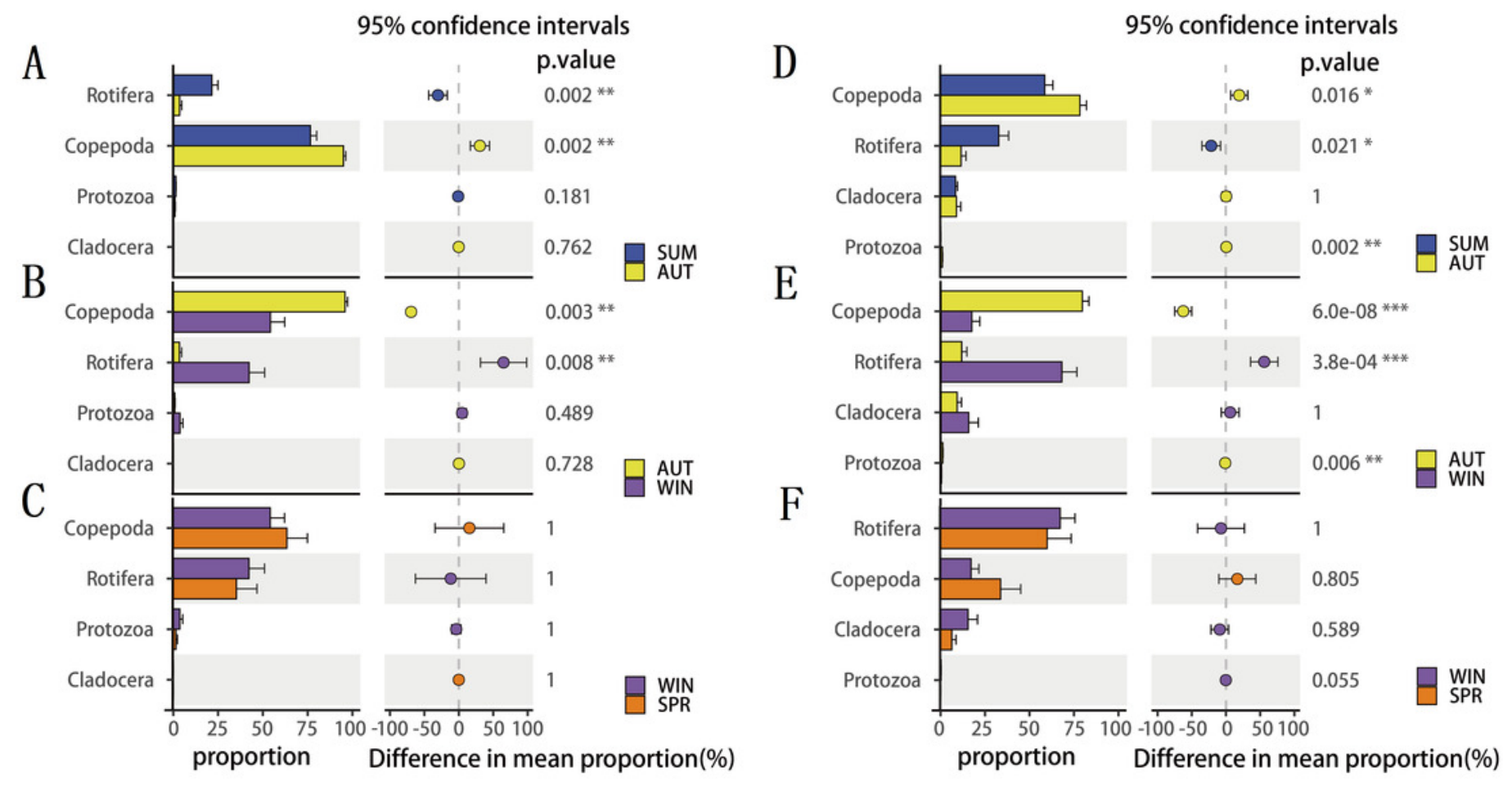


\section{Figure 6}

Clustering of the entire zooplankton community assemblages by sampling season using principal coordinate analysis (PCOA) based on the Jaccard dissimilarity index and BrayCurtis dissimilarity index.

(A) 185 Jaccard dissimilarity index; (B) 18S Bray-Curtis dissimilarity index; (C) COI Jaccard dissimilarity index; (D) COI Bray-Curtis dissimilarity index. 


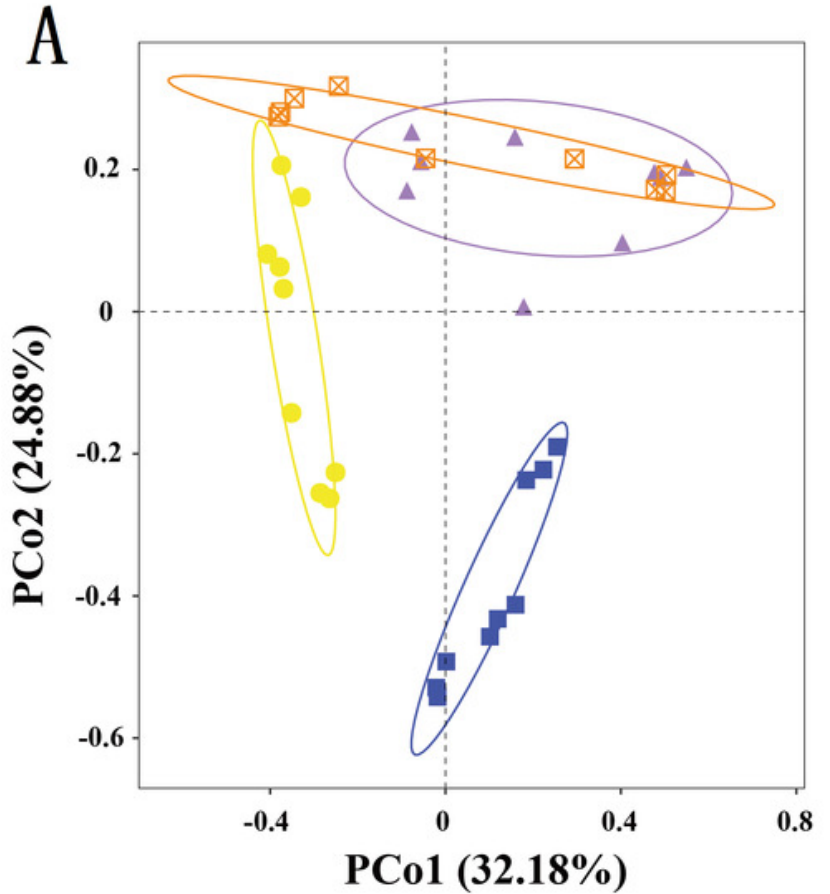

$\square \mathrm{SUM}$ AUT $\triangle$ WIN $\triangle \mathrm{SPR} 8$ 8 $75 \%$ confidence intervals

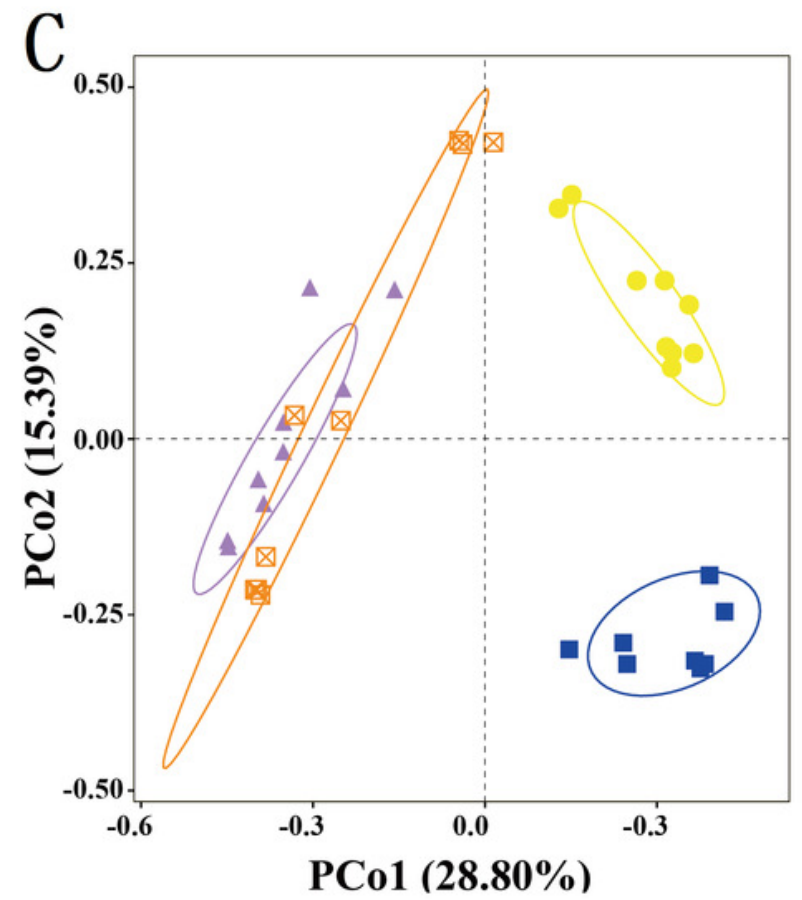

$\square$ SUM AUT $\triangle$ WIN $\triangle \mathrm{SPR} 8875 \%$ confidence intervals

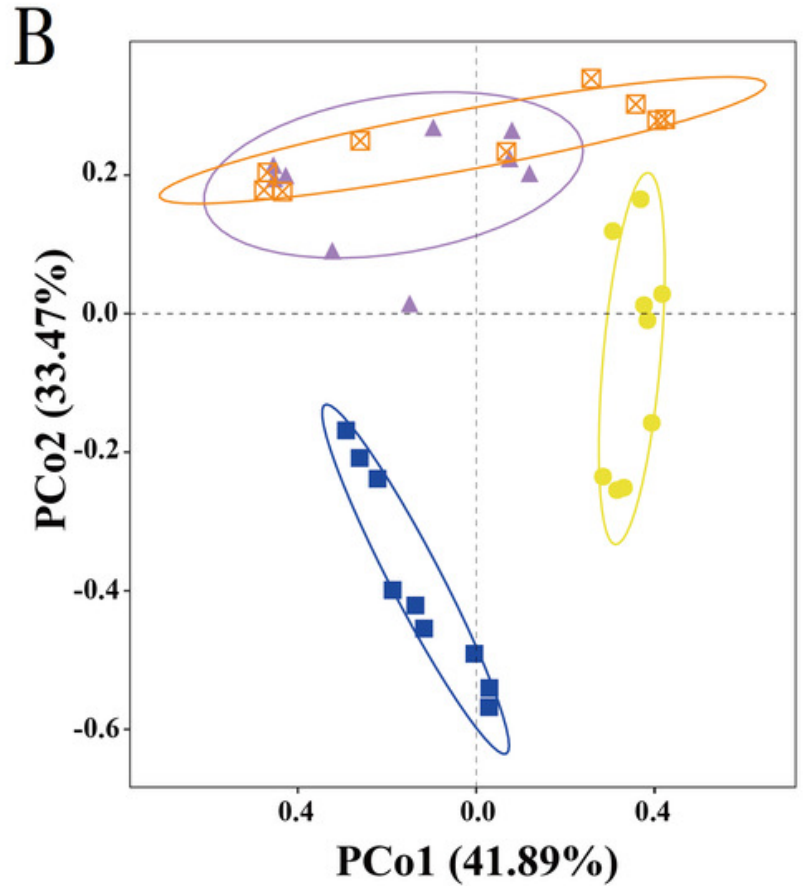

口SUM AUT $\triangle$ WIN $\triangle \mathrm{SPR}$ \&० $75 \%$ confidence intervals

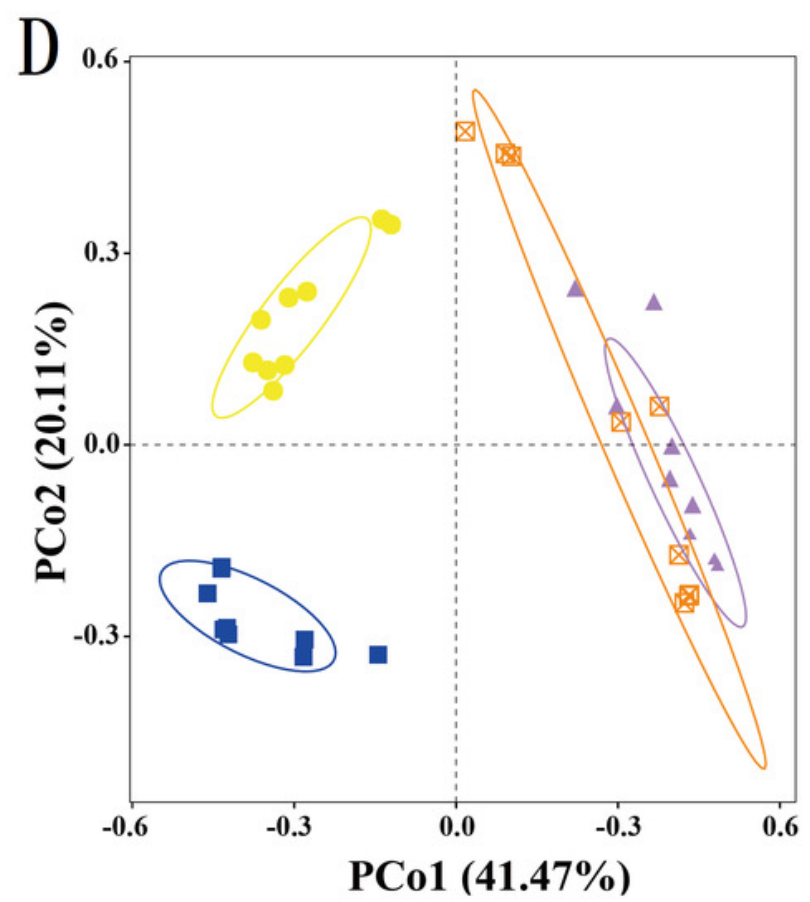

口SUM AUT $\triangle$ WIN $\triangle \mathrm{SPR}$ \&8 $75 \%$ confidence intervals 
Figure 7

Relative abundance of all samples in different sampling seasons at the genus level.

(A) $18 \mathrm{~S}$ rRNA; (B) COI. 

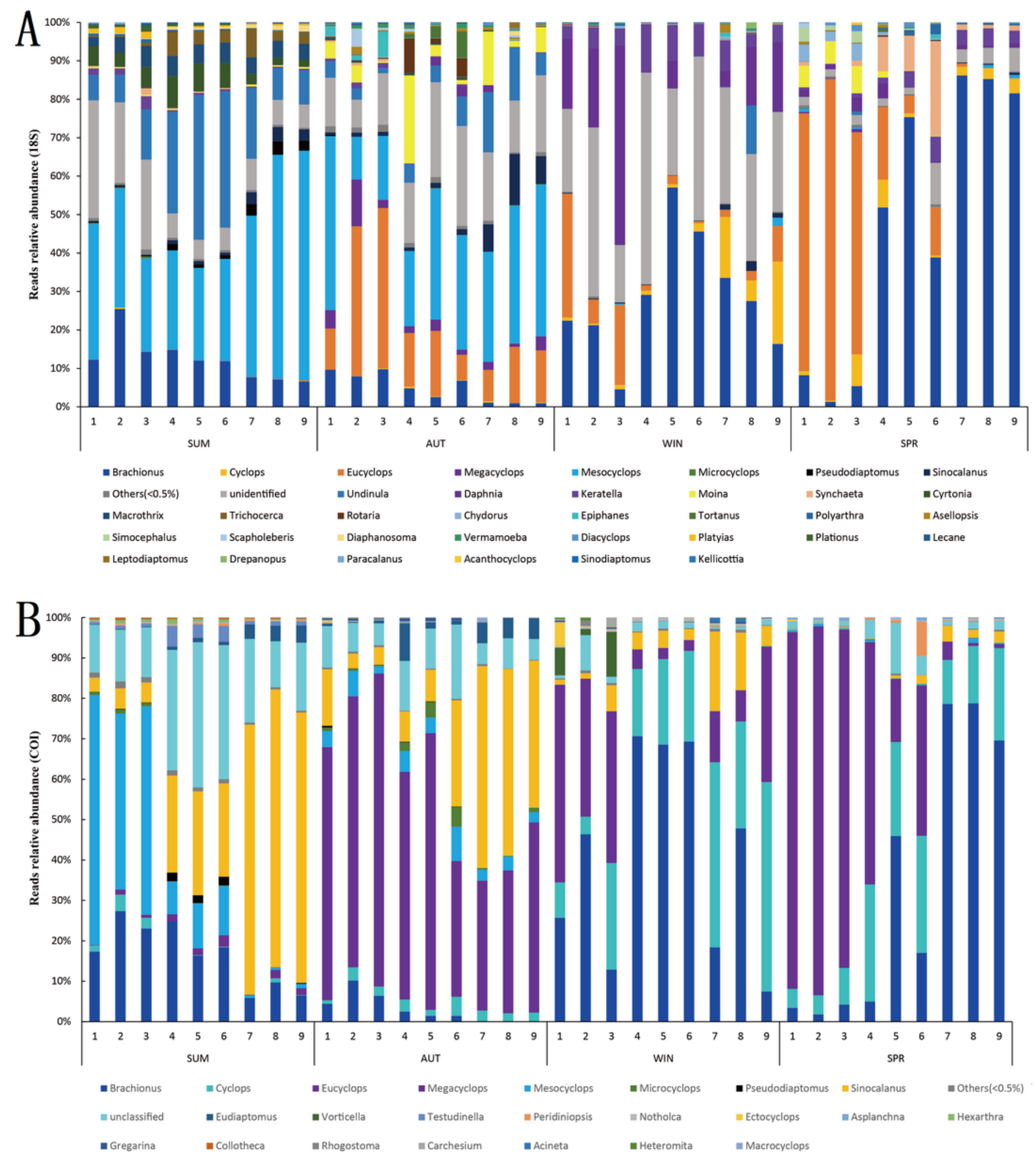


\section{Figure 8}

Water environmental factors driving seasonal changes in the zooplankton community.

Pairwise comparison of water environmental factors was achieved by using Spearman tests, and the color gradient represents Spearman's correlation coefficient. OTUs from different metabarcoding datasets (18S rRNA, COI) were related to water environmental factors by using partial (geographic distance-corrected) Mantel tests. Edge width: Mantel's R statistic; edge color: statistical significance (based on 9,999 permutations). (A) 18S rRNA; (B) COI. 
A

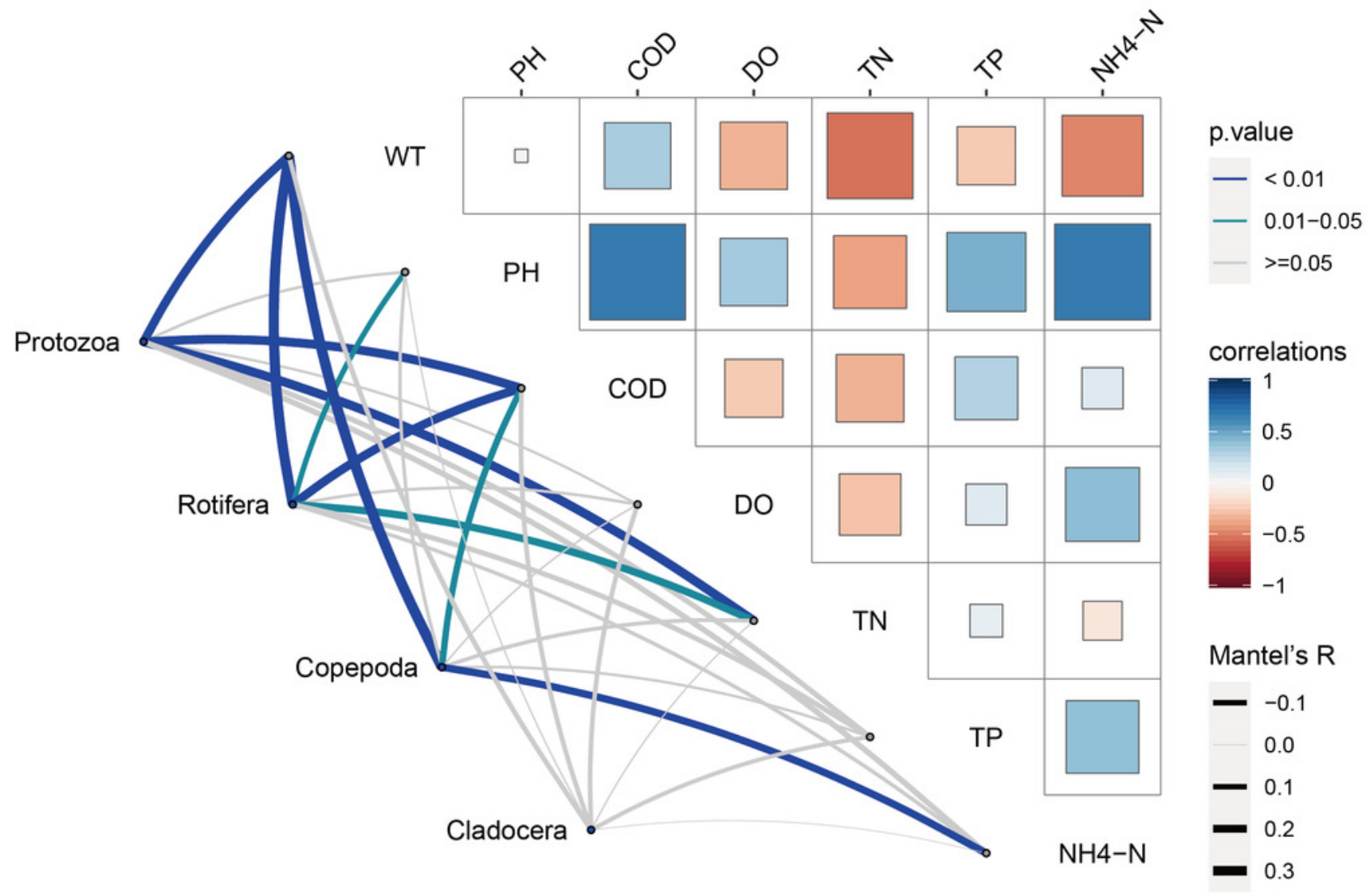

B

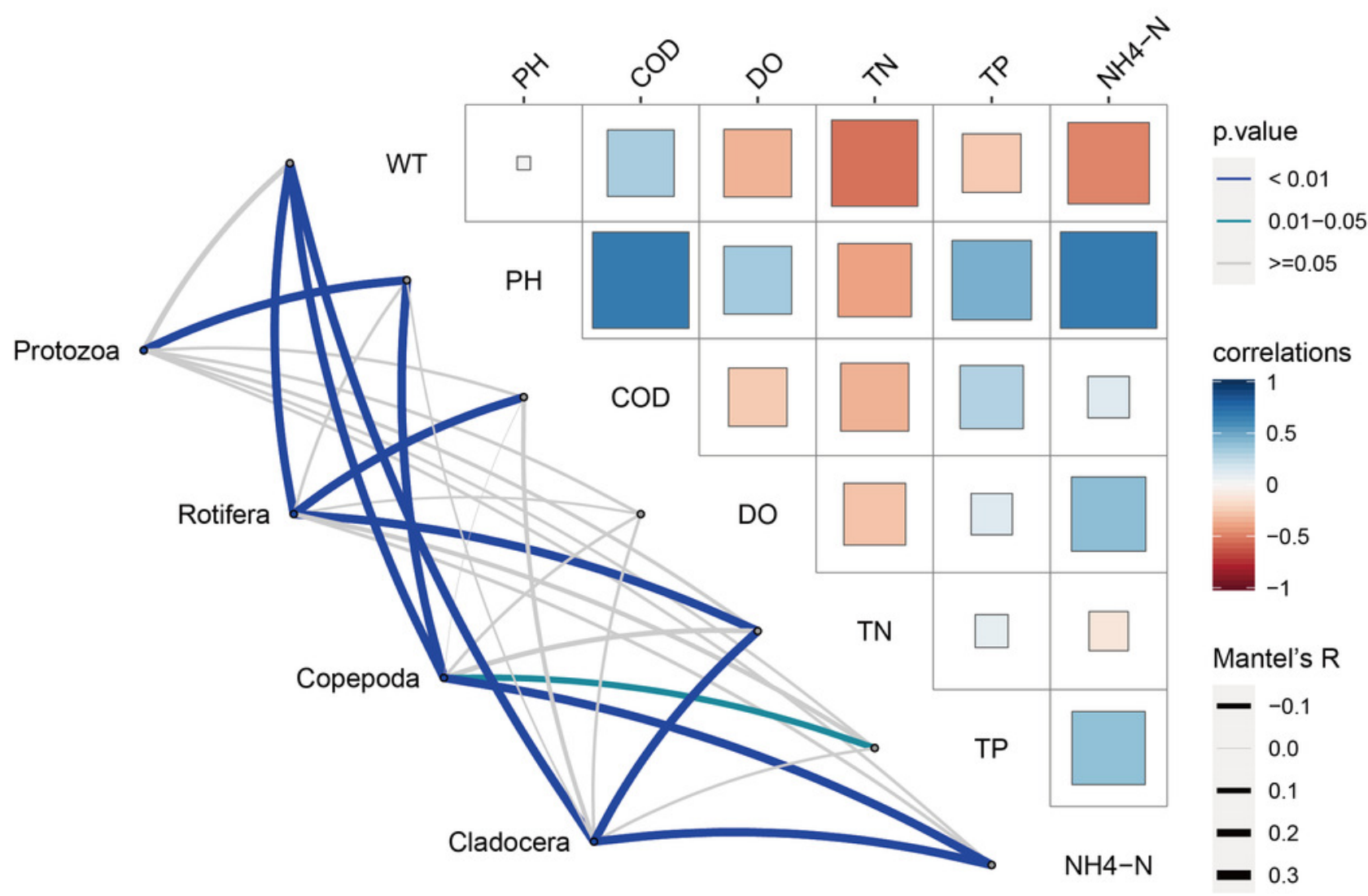


Figure 9

Canonical correspondence analysis (CCA) of the relative abundance of the zooplankton community in different metabarcoding datasets.

WT, water temperature; $\mathrm{pH}, \mathrm{pH}$; COD, chemical oxygen demand; TP, total phosphorus; NH4$\mathrm{N}$, ammonium; TN, total nitrogen. (A) 18S rRNA; (B) COI.
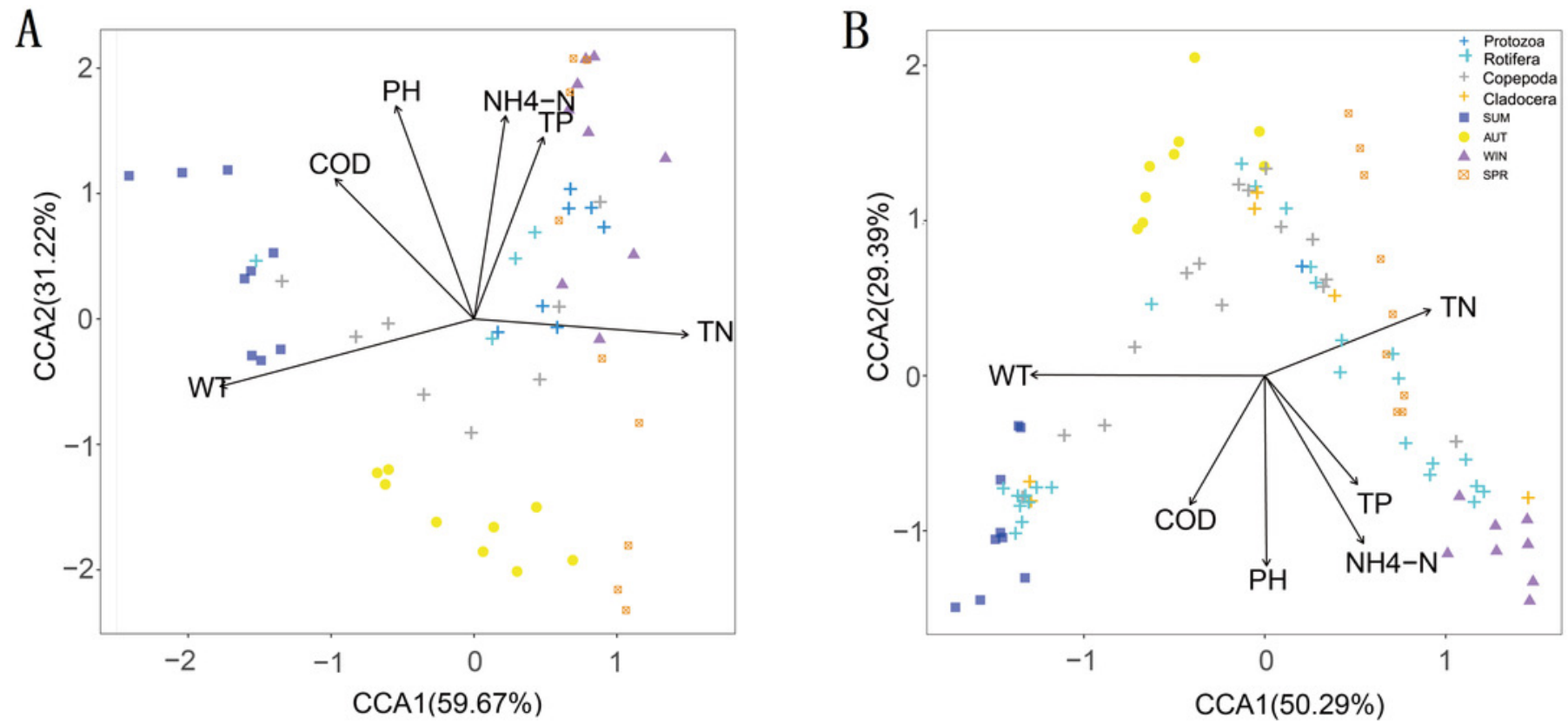